\title{
LIVVkit 2.1: automated and extensible ice sheet model validation
}

\author{
Katherine J. Evans ${ }^{1}$, Joseph H. Kennedy ${ }^{1}$, Dan Lu ${ }^{1}$, Mary M. Forrester ${ }^{2}$, Stephen Price $^{3}$, Jeremy Fyke ${ }^{3, a}$, \\ Andrew R. Bennett ${ }^{4}$, Matthew J. Hoffman ${ }^{3}$, Irina Tezaur ${ }^{5}$, Charles S. Zender ${ }^{6}$, and Miren Vizcaíno ${ }^{7}$ \\ ${ }^{1}$ Computational Earth Sciences Group, Oak Ridge National Laboratory, Oak Ridge, TN, USA \\ ${ }^{2}$ Department of Geology and Geological Engineering, Colorado School of Mines, Golden, CO, USA \\ ${ }^{3}$ Fluid Dynamics and Solid Mechanics Group, Los Alamos National Laboratory, Los Alamos, NM, USA \\ ${ }^{4}$ Department of Civil and Environmental Engineering, University of Washington, Seattle, WA, USA \\ ${ }^{5}$ Sandia National Laboratories, Albuquerque, NM, USA \\ ${ }^{6}$ Departments of Earth System Science and Computer Science, University of California, Irvine, CA, USA \\ ${ }^{7}$ Department of Geoscience and Remote Sensing, Delft University of Technology, Delft, the Netherlands \\ anow at: Associated Engineering, Vernon, BC, Canada
}

Correspondence: Katherine J. Evans (evanskj@ornl.gov)

Received: 9 March 2018 - Discussion started: 29 March 2018

Revised: 18 December 2018 - Accepted: 13 February 2019 - Published: 22 March 2019

\begin{abstract}
A collection of scientific analyses, metrics, and visualizations for robust validation of ice sheet models is presented using the Land Ice Verification and Validation toolkit (LIVVkit), version 2.1, and the LIVVkit Extensions repository (LEX), version 0.1. This software collection targets stand-alone ice sheet or coupled Earth system models, and handles datasets and analyses that require high-performance computing and storage. LIVVkit aims to enable efficient and fully reproducible workflows for postprocessing, analysis, and visualization of observational and model-derived datasets in a shareable format, whereby all data, methodologies, and output are distributed to users for evaluation. Extending from the initial LIVVkit software framework, we demonstrate Greenland ice sheet simulation validation metrics using the coupled Community Earth System Model (CESM) as well as an idealized stand-alone high-resolution Community Ice Sheet Model, version 2 (CISM2), coupled to the Albany/FELIX velocity solver (CISM-Albany or CISMA). As one example of the capability, LIVVkit analyzes the degree to which models capture the surface mass balance (SMB) and identifies potential sources of bias, using recently available in situ and remotely sensed data as comparison. Related fields within atmosphere and land surface models, e.g., surface temperature, radiation, and cloud cover, are also diagnosed. Applied to the CESM1.0, LIVVkit identifies a positive SMB bias that is focused largely around Greenland's southwest region that is due to insufficient ablation.
\end{abstract}

Copyright statement. This paper has been authored by UT-Battelle, LLC under contract no. DE-AC05-00OR22725 with the U.S. Department of Energy. The United States Government retains and the publisher, by accepting the article for publication, acknowledges that the United States Government retains a non-exclusive, paid-up, irrevocable, worldwide license to publish or reproduce the published form of this paper, or allow others to do so, for United States Government purposes. The Department of Energy will provide public access to these results of federally sponsored research in accordance with the DOE Public Access Plan (http://energy.gov/ downloads/doe-public-access-plan).

\section{Introduction}

About $10 \%$ of human settlement is currently and will likely continue to be clustered in regions potentially vulnerable to sea level rise (SLR) (McGranahan et al., 2007), which will arguably result in some of the most devastating impacts of climate change. The polar ice sheets, and their peripheral glaciers, referred to hereafter as "land ice", represent the largest potential source of SLR in a warming climate through (1) increased meltwater runoff that is not compensated by increasing snowfall (Fettweis et al., 2013; Noël et al., 2015) and (2) increased ice discharge (calving and marine melt) (Church et al., 2013). In order to provide credible predictions of SLR to policymakers and stakeholders, scientists need accurate representations of land ice as simulated within Earth system models (ESMs). 
The scientific community's "best" projections of ice sheet mass change rely on process-based models and, increasingly, model-ensemble projections from stand-alone ice sheet models (ISMs) (Church et al., 2013). To provide optimal results, these ice sheet models must include accurate representations of ice sheet dynamics, physics, and coupling schemes (e.g., to obtain forcing from other components, like the ocean and atmosphere). As these models are connected to coupled ESMs, coupled-model initialization procedures and a quantitative understanding of key model sensitivities and uncertainties (Vizcaíno, 2014) are also required. These challenges are well recognized: there is an ongoing effort within coupled ESMs to develop a dynamically active ISM (Lipscomb et al., 2013; Barbi et al., 2014; Ziemen et al., 2014) as well as highresolution and high-fidelity stand-alone ISMs (Larour et al., 2012; Aschwanden et al., 2016). Furthermore, the ISM community has organized a number of intercomparisons under the umbrella of the Ice Sheet Model Intercomparison Project (ISMIP6) that are currently underway (Nowicki et al., 2016; Goelzer et al., 2018) to better understand and compare the distribution of ISM predictions. These could also be used to track model development.

Of course, there are limitations with all models; they are an imperfect representation of actual observed behavior. It is critically important to identify and quantify their most notable biases and discrepancies in order to maximize the impact of model improvements and to increase confidence in model predictions. However, the paucity of observational data in the polar regions, especially data that are specifically relevant to ice sheets themselves, has prevented a comprehensive assessment of ISM and coupled ESM-ISM skill, and key climatological forcings that drive ISM evolution. Although technology has enabled a significant growth in glacier and ice sheet observations via in situ, airborne, and satellitebased systems in the last decade, this short time frame can only provide current information because ice sheets, more than other aspects of the surface climate system, evolve over much longer timescales. Of course it is not possible to execute experiments in a lab setting where one could adjust parameters to develop an account of the sensitivities of the land ice system. While theoretical underpinnings can be used to develop insight toward model sensitivities (refer to Schoof and Hewitt, 2013 for a review and summary of progress), these constructs are also limited by our current understanding of the drivers of ice sheet evolution.

With the aim of facilitating large-scale development and execution of ISM and coupled ESM-ISM experiments, and determining the degree to which they sufficiently represent aspects of the actual Earth system, we present the software and data package LEX (Kennedy et al., 2018b), a validation extension to the Land Ice Verification and Validation toolkit (LIVVkit; Kennedy et al., 2018a), which provides a basic but extensible capability to assess ice sheet models within, and independent of, coupled ESM configurations (hereafter, LIVVkit and LEX will collectively be referred to as sim- ply LIVVkit). The philosophy of verification and validation $(\mathrm{V} \& \mathrm{~V})$, using terminology and standards from Oberkampf and Roy (2010), and its adoption by the LIVVkit to verify ice sheet model simulations is presented and discussed in Kennedy et al. (2017). Efforts to validate both ISM and ISM-ESM behavior, including a new capability to compare ESM-derived surface mass balance against recently available observations, are detailed here.

\section{Target simulations and comparison data}

\subsection{Target simulations for analysis}

In order to demonstrate the validation features of LIVVkit, we analyze output from two Greenland ice sheet (GrIS) simulations from (1) a high-resolution ISM and (2) a global, fully coupled ESM from which ISM forcing is derived. Both have been presented in the literature and made available to us, which allows us to verify the software for use by others with confidence and complement existing community validation efforts.

For the high-resolution Greenland ISM simulation (1), data were generated from the Community Ice Sheet Model, version 2 (CISM2; Price et al., 2015), coupled to the Albany/FELIX velocity solver (Tezaur et al., 2015a, b), hereafter referred to as CISM-A. These simulations are described in detail by Price et al. (2017). This configuration is selected to highlight how LIVVkit could be used to validate a standalone simulation that can then be used as an initial condition for follow-on simulations. The simulation used here includes a dynamic ice sheet component forced by a time-varying surface mass balance (SMB) field. It spans the years 19912013, although these dates should be considered a generic present-day period because the data assimilation techniques used for the initialization used multiple datasets from the last 20 years. The initial state was generated through a multi-step procedure to produce balanced internal temperature and velocity fields, which was then forced by surface mass balance anomalies from the Regional Area Climate Model (RACMO, version 2; van Angelen et al., 2013). The goal in creating these simulations was to illustrate the use of the Cryospheric Model Comparison Tool $(\mathrm{CmCt})$, an ice sheet model validation tool that focuses primarily on the preprocessing necessary to facilitate the comparison of satellite data to ISM output (Nowicki et al., 2017). That effort is complementary to the validation software presented here, which focuses on comparisons to in situ and remotely sensed data from other sources.

For the coupled ESM (2), we analyze output from the atmosphere (Neale et al., 2013) and land surface (Lawrence et al., 2012) components within a global, fully coupled simulation from the Community Earth System Model (CESM version 1.0.6; CSEG, 2014). For this model, the ice sheet surface mass balance (accumulation of less runoff and sublima- 
tion) is calculated within the snowpack model of the land surface component and then downscaled to the relatively higherresolution ice sheet grid in order to provide SMB forcing for the ISM component (Rutt et al., 2009), as described in Lipscomb et al. (2013). Details about the simulation and the SMB are presented in Vizcaíno et al. (2013) (hereafter V13). Here, we focus on a historical, transient simulation spanning 1850-2005, although we restrict our analysis to 1960-2005 except where noted to avoid issues related to model spin-up. Hereafter, we refer to this simulation as CESM.

\subsection{Comparison data specific for ISM}

ISMs that use a data assimilation approach to most closely reproduce present-day conditions for their initial state and forcing (as compared to those that are spun up from pre-industrial or earlier states) currently use much of the most informative observational data for model initialization. As an example to move the community towards robust present-day validation, we apply LIVVkit to generate and present model-data comparisons using as many available datasets as possible and including those that are used for model initialization.

For validation of surface velocity and ice thickness, the data available for comparison are initialization data. These were obtained using a partial differential equation (PDE)constrained optimization procedure (Perego et al., 2014). We include these in LIVVkit with the expectation that independent data will replace these data within the same workflow going forward. LIVVkit makes use of a GitHub repository of scripts and procedures (Kennedy, 2017) that procures the surface velocity and thickness datasets from a host of publicly available sources. The workflow processes this dataset to create a number of fields of variables in an expected format, with all the masking and projections necessary for postprocessing in LIVVkit (explained in Sect. 3). The velocity fields used for comparison originate from the NASA Making Earth System Data Records for Use in Research Environments (MEaSUREs) program, which provides annual icesheet-wide velocity maps for Greenland, derived using Interferometric Synthetic Aperture Radar (InSAR) data from the RADARSAT-1 satellite (Joughin et al., 2010a, b). The dataset currently contains ice velocity data for the winters of 2000-2001 and 2005-2006, 2006-2007, and 2007-2008 acquired from RADARSAT-1 InSAR data from the Alaska Satellite Facility (ASF), and a 2008-2009 mosaic derived from the Advanced Land Observation Satellite (ALOS) and TerraSAR-X data. For bed topography and ice thickness, we use the Greenland Ice Mapping Project digital elevation model (GIMP DEM; Howat et al., 2014) for topography of the ice-free areas, and the Morlighem et al. (2014) bed topography and ice thickness estimates, which are derived from ice surface elevation data, airborne radar soundings from Operation IceBridge, and the GIMP DEM (as a reference surface). It is straightforward to update and/or augment these same data with new years and locations as they become available (e.g., Morlighem et al., 2017).

\subsection{Comparison data specific for ESM}

In the case of coupled ESM validation for ISM development, modelers will benefit from more focused and quantitative evaluation in the vicinity of the GrIS, as compared to the global and regional model validation typically provided with the release of components that comprise ESM. Therefore, LIVVkit provides validation of the atmosphere and land surface components in ESMs specifically over the GrIS region for key variables that affect it. Validation of the atmosphere and land surface is still limited by the availability of observed data over the GrIS (and Antarctic ice sheet), whether it is used directly or within reanalysis products. As with the ice sheet data, additional regional in situ and remotely sensed data will improve LIVVkit and are a target for further development.

From LIVVkit, the examples presented in Sect. 4.2 include cloud fractions from an ESM, which are compared to the International Satellite Cloud Climatology Project (ISCCP) (Rossow and Schiffer, 1999) and the combined CloudSat radar and Cloud-Aerosol Lidar with Orthogonal Polarization (CALIOP) lidar datasets (hereafter CLOUDSAT) (Kay and Gettelman, 2009) reanalysis products. ISCCP resolves the diurnal cycle, within which monthly averages are created, and provides the longest available time record. CLOUDSAT covers only a short time record; however, the detection techniques are considered superior for the Arctic. The interested reader is referred to the Climate Data Guide (Pincus and NCAR Research Staff, 2016) for more details about the attributes and limitations of these datasets.

\subsection{Surface mass balance comparison data}

Given the dependence of ice sheet evolution on surface mass balance, LIVVkit tracks SMB for both coupled ESM and stand-alone ISM, even if it is provided as a forcing for a simulation for the ISM. For an ice-sheet-wide view of SMB behavior, LIVVkit presents metrics relative to the most recently available version of RACMO, version 2.3 (RACMO2.3), the characteristics of which are summarized in Noël et al. (2015). The configuration of RACMO2.3 has been specifically designed and validated for its fidelity in capturing the extended Greenland region. As with initialization data, modelto-model comparisons of SMB data do not provide independent validation. This is especially true when applied to a stand-alone ISM that has been forced with model SMB, as is the case for CISM-A, which has been forced with RACMO2.0 (presented in Sect. 4.1). We include these comparisons within LIVVkit because it is useful (1) when presented against ESM SMB and (2) to have available when monitoring other aspects of ice sheet evolution to attribute sources of bias. RACMO2.3 data are provided at approx- 
imately $11 \mathrm{~km}$ horizontal resolution with 40 vertical layers and include the GrIS and other nearby areas. LIVVkit is currently configured to compare years 1980-1999 of the RACMO2.3 simulation because it was forced with the more recent ERA-Interim reanalysis data (Stark et al., 2007; Dee et al., 2011) from 1979 to 2014, and many of the model development runs for Earth system models cover the period spanning 1979-2000 as part of the Atmospheric Model Intercomparison Protocol (AMIP-II) (Gleckler, 2004).

To provide independent validation of an ESM SMB field, LIVVkit compares in situ SMB values using 623 core/pit/stake measurements from a diversity of sources. Many of these were included in Vizcaíno et al. (2013, Fig. 6) but have been updated in LIVVkit with new data and selection criteria. For a station to be included, it must contain a record of location, elevation, and observation start/end dates. Here, we use 387 locations out of a possible 450 from a collection of accumulation-zone (net specific SMB >0) estimates compiled by Cogley (2004) using data from Ohmura and Reeh (1991), Ohmura et al. (1999), and Bales et al. (2001). In addition to the stations included from Bales et al. (2001), 38 additional ice cores from the Program for Arctic Regional Climate Assessment (PARCA) (Bales et al., 2009) have been added, with six of those as replacements to the earlier 2001 study. The PARCA compilation also includes reanalyses of time series from 20 coastal weather stations to estimate SMB; however, only estimates from ice cores and snow pits are currently included in LIVVkit. We also include data from the Programme for Monitoring of the Greenland Ice Sheet (PROMICE), a compilation of glacier explorations and in situ measurements taken since the 1960s from the GrIS ablation zone (SMB < 0) (Machguth et al., 2016). From 790 original locations, all but 198 stations were excluded based on the following criteria:

- unknown elevation or start or end date of observation period;

- observation period was less than $95 \%$ of a year (i.e., seasonal data);

- accumulation data were derived using a methodology other than pit/core measurements (e.g., weather stations or surface lowering relative to ramp road).

For all stations, temporal data were aggregated and treated as typical climatology, regardless of the record length. If annual SMB estimates were supplied for multiple years, LIVVkit averages over all years to provide a single annual value for each location. Because station selection is subject to various adjustments based on the type of validation to be performed, we choose these selection criteria to facilitate a general starting-point comparison.

Model results are also compared to accumulation estimates derived from 25 NASA Operation IceBridge radar airborne flights from the 2013 and 2014 seasons as detailed in
Lewis et al. (2017) and the associated supplementary data. The measurements capture internal reflecting horizons in the top few hundred meters of the ice sheet, which can be used to estimate the historical SMB record spanning the past three centuries. The IceBridge data from Lewis et al. (2017) are provided as raw estimates seasonally for a given lat/long coordinate. Because the temporal record varies for each site, LIVVkit calculates annually averaged SMB at each location.

In order to provide basin-scale estimates of SMB, we use the Zwally et al. (2012) drainage basin delineations as visualized by color in Fig. 1 (colors) and with numbering conventions preserved. This figure also illustrates the location and extent of basin-wide SMB data, including pit/core locations (filled shapes) and IceBridge altimetry transects (white lines). Accumulation-zone SMB estimates from Cogley (2004) and Bales et al. (2009) PARCA cores are shown as blue circles, while ablation-zone PROMICE data (Machguth et al., 2016) are shown as yellow triangles. The data points are sized by the length of their temporal record, with larger markers indicating that estimates were averaged from a greater number of annual SMB values.

Processing the IceBridge data from Lewis et al. (2017), which are provided as raw estimates seasonally for a given latitude/longitude coordinate, is a two-step process in LIVVkit. Each model cell is assigned to a Z12 basin. LIVVkit does this by converting the Z12 drainage basin outlines into polygons, and then decides which polygon contains which model cell centers. If a model cell center is not within any of the basin polygons, it is assigned basin " 0 ". Correspondingly, each IceBridge measurement at a lat/long location is averaged over seasons to obtain an annual SMB value. Some locations have older SMB records so the average annual SMB value used for comparison to the model is the mean over all available temporal records. Then, a kdtree/nearest-neighbor method is used to find the model cell closest to the observed lat/long measurement. Thus, the Z12 basin at that location will be the same one as the corresponding model cell, found in the first step.

The present strategy to include both observational and model comparison data was chosen to maximize (1) clarity (the scientist understands the limitations of the information); (2) reproducibility (automation within LIVVkit); and (3) extensibility (users can add additional data for their own comparisons with minimal local adaption of the code). For provenance, changes to LIVVkit's inclusion of new data are controlled through releases so users can be certain of the data they are comparing for a given tag of the data repository. LIVVkit can be altered at will once the code is forked or downloaded locally to suit the user's needs. The step to process comparison data is a separate step explained in Sect. 3, but it is automated and fully documented. A discussion about potential new candidate data to add to the current collection is provided in Sect. 5. Additional details and references to the comparison data can be found on the GitHub site (Kennedy et al., 2018a). 


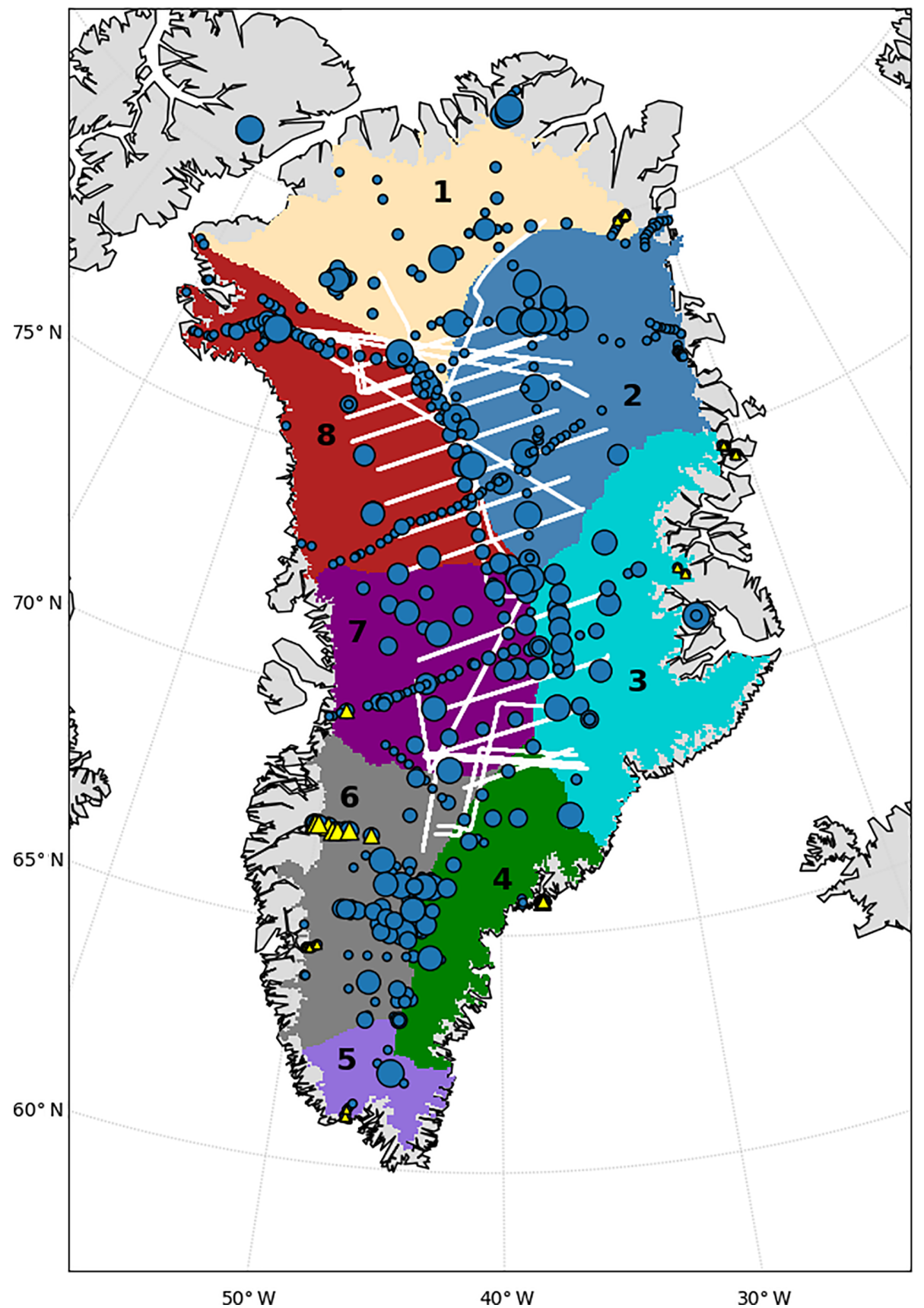

Figure 1. Greenland ice sheet drainage basin delineations (colored and numbered regions) as in Zwally et al. (2012), the location and temporal extent of the pit/core locations (filled circles and triangles), and the altimetry transects (white lines) used in LIVVkit SMB analyses. The basin numbers follow Zwally's designation and the colors correspond to those used in histograms and scatter plots throughout. Pit/core data points are sized by the length of their temporal record, with larger points indicating annual estimates were taken from a greater number of yearly SMB values.

\section{Software infrastructure for validation}

LIVVkit is a Python-based, open-source software package designed for verification and validation of ice sheet and Earth system models. LIVVkit operates on model output, viewing the model as a black box. This strategy provides flexibility in analyzing many different models, assuming some basic conventions are followed. LIVVkit is installable through Anaconda/Miniconda, PiPy, or GitHub, and provides the Iivv command line interface (CLI), which is used to execute the analyses and output the results to a portable website on the user's local machine. The details of the design philosophy, 
construction, and verification components of LIVVkit are described in detail along with an example of validation to show the structure of the overall toolkit in Kennedy et al. (2017). A robust validation capability for ESM and ISM, which includes modules for postprocessing and organization of model and observational data and the creation of plots, tables, and metrics, is presented here.

There are three major steps to validate a model simulation (or set of simulations): (1) gathering the required observational and model output data, (2) postprocessing the observational and raw model output data to make comparable data products, and (3) running the analyses and creating visualizations of the prepared data products. On the observational side, steps (1) and (2) require a significant amount of time investment (up to $70 \%$ of the time spent on analytics projects; Terrizzano et al., 2015) due to the disparate nature of observational data reporting, the large variety of formats involved, and the expertise often needed to correctly manipulate observing data. Similarly, for both modeling and observational data, a significantly large, and ever-increasing, amount of data needs to be moved from raw data storage locations to the analysis machine. For example, NASA's Earth observing data are expected to grow to 50 PB by 2020 (Lynnes and Ramachandran, 2018). Similarly, even the icesheet-only CISM-A simulation data described above constitute well over $200 \mathrm{~GB}$ of data.

To deal with the challenges surrounding steps (1) and (2), either the observing data are brought to an analysis machine co-located with the model data or the model data are brought to an analysis machine co-located with the observations (and observational specialists). Due to the sophistication required for analysis of GRACE data, Price et al. (2017) and Nowicki et al. (2017) have taken the latter approach. However, workflow is hard to integrate into a model development cycle, especially one using automated testing, and so moving processed observational data to analysis machines at modeling centers is the preferred approach by Earth system models (e.g., CESM; Vertenstein et al., 2013). In either approach, the data being moved are processed into a comparable product before the movement happens in order to reduce the amount of data transferred. Even so, the data repository for CESM is well over 1 TB in size (Vertenstein et al., 2013).

LIVVkit has taken a hybrid approach of the two strategies by developing a LIVVkit Extensions (LEX) package (Kennedy et al., 2018b), which is available via GitLab repository, under a modified BSD open-source license, hosted at Oak Ridge National Laboratory (ORNL; Kennedy et al., 2018b). The repository holds a collection of validation analysis extension to LIVVkit, as well as observational and model data by utilizing git large file support ( $g i t-l f s$ ). Each analysis in LEX is required to provide at minimum the required processed observational data; a README describing the original data, how to acquire them, and any rehosting/licensing issues associated with the data; a BibTeX file containing any relevant citations; postprocessing scripts used to generate the processed data; and a minimal set of model data such that an example analysis can be run. The LEX repository is already sizable, as it contains some large (gigabyte-scale) observations datasets, and is expected to grow to unwieldy proportions as more observational data are included and older datasets are updated. In order to handle the projected size of this repository, LIVVkit details the commands necessary to only clone the analysis files without the data files (e.g., the description, configuration, and BibTeX files) in order to see which analyses are available, and then pull down just the latest version of the required data to run the analyses. This allows both observationalists and modelers to co-develop the analyses available by always having a minimal working example available. Further facilitating this co-development is the GitHub-like interface provided by the GitLab instance which allows code and datasets to be commented on, issues to be raised, and development goals and tasks to be outlined.

For the model and observation data discussed here, LEX provides a set of single-execution, task-parallel postprocessing (bash) scripts designed for automated postprocessing of output at LCFs, so that the data are prepared for scientific analysis through (and outside of) LIVVkit. These scripts can be adapted for other systems, although smaller computing systems may limit the user to lower-resolution data as a target. Earth system models are comprised of multiple component models (e.g., land, ocean, atmosphere, sea ice, land ice) that may either be active or provided as a data model, depending on the configuration selected. LIVVkit currently targets the atmosphere, land surface, and ice sheets if they are active, creating a new directory set by the user that contains subdirectories for each component and all their final data products, including their incumbent metadata and associated masking and mapping files. This enables full reproducibility and structure for additional analysis within or independent of LIVVkit.

The postprocessing scripts use a combination of Python and NetCDF operators (NCOs) (Zender, 2008), an opensource collection of programs that operate on a diversity of scientific data. They use ncclimo commands within versions $\mathrm{NCO} / 4.6 .9$ and later to facilitate the extraction of monthly, seasonal, and annual means (and optionally, to regrid the data) as well as its baseline commands to average, sum, produce weighted and masked data, and other operations typically used in geoscientific analyses. NCO addresses provenance and transparency by appending the specific details of operations within the metadata of datasets it processes and it performs task parallelism where applicable.

For stand-alone ice sheet model output (i.e., where climate forcing fields such as surface temperature and surface mass balance are not provided from coupling to a climate model), LIVVkit processes the SMB data used to force the model, thickness, three-dimensional temperature and horizontal velocity, and surface elevation, and it assumes that the data are located within a single file. From the velocity components, it 
will create the velocity norms. When complete, the postprocessed data directory contains

- multi-year monthly, seasonal, and annual climatologies (time averages) over the selected period for all variables;

- time series of all variables and their annually and areaweighted averages over the length of output for selected variables; and

- annual and seasonal ice sheet mask area-weighted and GrIS-masked averages for selected variables over the selected period of analysis.

For GrIS-masked data, values are averaged over a region defined by a minimum ice thickness $(0.001 \mathrm{~m}$ default, used for this analysis). For velocity, areal averages are computed over the cells where they are defined.

When processing large-scale coupled Earth system model simulations, to which an active ice sheet may or may not be coupled, LIVVkit targets radiation, thermodynamics, hydrological, and dynamical variables that influence ice sheet evolution. This process is more extensible and robust than for stand-alone ice sheet model processing, as coupled models more closely follow metadata conventions. For the coupled model, the completed postprocessed data directory contains

- multi-year monthly, seasonal, and annual climatologies over the selected period for all variables;

- time series of annually and area-weighted averages and GrIS masked for selected variables, each in a separate file, over the length of output;

- annual and seasonal area-weighted and GrIS-masked averages for selected variables over the selected period of analysis; and

- annualized daily averages for selected variables over the full length of the simulation

within subdirectories for each component. Processing these high-resolution data requires computing nodes with high memory. These "fat" nodes can be accessed using batch nodes at LCFs, and LIVVkit's processing scripts handle the batch queue submission.

It is important to acknowledge that there are numerous intellectual property concerns with hosting and redistributing datasets. To partially satisfy these concerns, LIVVkit uses the data description to provide some context to the analysis and requests that the original data authors are cited in any publication which utilizes the analyses for testing, development, or scientific analysis. The appropriate citations, detailed in the provided BibTeX file, are listed on the output website. Additionally, LEX maintains a public-private development cycle where analyses are developed in a private git repository (also hosted at ORNL) and only released to the public repository once dataset author/maintainer permission is provided (LIVVkit itself is publicly developed). For analyses that rely on datasets where permission cannot be granted, LIVVkit will provide a description of how to acquire the data and scripts to process the data for analysis.

Currently, the LIVVkit development team is pursuing partnerships with data providers like NASA and NSIDC to reduce or eliminate the time to get new analyses into the public LEX repository. We note that the lack of standards/adoption and/or metadata conventions, e.g., CF conventions, has been the biggest challenge for the rapid inclusion of a dataset in LEX, rather than intellectual property concerns.

Once the postprocessing is complete, the prepared model and observational/comparison data are analyzed over a suite of time and space slices and are provided to the users in a combination of easily digestible text, tables, and figures. A validation analysis is initiated by pointing the LIVVkit execute command, 1 ivv, to a $\mathrm{JSON}^{1}$ configuration file that specifies the analysis details:

\section{livv --validate /path/to/analysis.json -o \$OUTDIR -s}

Within the JSON configuration file, the user provides the type of model run and the location of the output and comparison data. The user may also specify the location where the output data and website will be placed when complete (via the -out-dir or -o option) and launch a simple HTTP server to host the website (via the -serve or $-\mathrm{s}$ option). When the HTTP server is launched, a direct hyperlink is printed on the command line to either the analyses that were just executed or a previous analysis selected via the CLI. For example, all the figures and analyses presented here can be reproduced by executing the following command from the top directory of LEX.

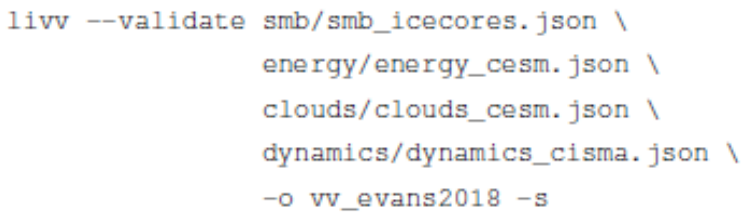

While any particular analysis performed by LIVVkit can be quite sophisticated, creating a new analysis in LIVVkit/LEX is intended to be straightforward for the user. The processes of building an extension is detailed in the LIVVkit documentation. A template validation analysis is provided within the software that details the minimal Python code needed to run an analysis script, along with a minimal template JSON configuration file. A user can place any external information needed by their analysis in the configuration file (e.g., paths to data, years to analyze, method switches). For sophisticated analyses, LIVVkit is also able to import analysis packages developed with a standard Python package structure as long as a configuration file and a LIVVkit

\footnotetext{
${ }^{1}$ JavaScript Object Notation is a lightweight, languageindependent tool that both machines and humans can parse.
} 
Table 1. Area-weighted and GrIS-masked annual averages for variables from CISM-A model output. "Input areal average" refers to the processed datasets from observations as described in Sect. 2 that are used for the initial state of the model before spin-up.

\begin{tabular}{|c|c|c|c|}
\hline Variable & Units & $\begin{array}{r}\text { Model } \\
\text { areal } \\
\text { average }\end{array}$ & $\begin{array}{r}\text { Input } \\
\text { areal } \\
\text { average }\end{array}$ \\
\hline SMB & $\mathrm{kg} \mathrm{m}^{-2} \mathrm{a}^{-1}$ & 259.0 & 255.9 \\
\hline Top layer temperature & ${ }^{\circ} \mathrm{C}$ & -2.3 & NA \\
\hline$U$ velocity & $\mathrm{ma}^{-1}$ & -8.3 & -14.5 \\
\hline$V$ velocity & $\mathrm{ma}^{-1}$ & -3.1 & -0.8 \\
\hline Velocity norm & $\mathrm{ma}^{-1}$ & 54.3 & 62.7 \\
\hline Ice thickness & $\mathrm{m}$ & 2179 & 1781 \\
\hline
\end{tabular}

NA: not available.

entry point are provided. The LEX repository also functions as a set of examples and contains both the basic script and package style analyses.

\section{Presentation and visualization}

Targeting stand-alone ice sheet and coupled Earth system model output within LIVVkit provides two common use cases of model evaluation of ice sheet behavior and drivers. A subset of these analyses is presented below, with a special focus on a basin-wide analysis of the surface mass balance using more recent observational data presented in Sect. 2.

\subsection{Stand-alone land ice model analysis}

Using GrIS simulation data, processed as described in Sect. 3, LIVVkit produces a website with metrics and plots for validation. As an overall check of model behavior and to identify potential large-scales biases, there is a table of annualized and areal average values over the selected time record for relevant variables, which includes the SMB forcing, dimensional velocity (e.g., zonal $(U)$ and meridional $(V)$ velocity components, respectively), and velocity norm. Table 1 displays a similar version of the table produced by LIVVkit as applied to the CISM-A simulation described in Sect. 2.

LIVVkit displays a suite of two-dimensional contour plots of climatological averages over the selected time record. Figure 2 presents the surface mass balance from CISM-A, RACMO2.3, and their difference. Because the CISM-A simulation was forced with RACMO2.0 and not RACMO2.3 data, there are differences between CISM-A and RACMO2.3 that mirror the differences between the RACMO versions, in particular the southwestern and northern melt regions and over strong accumulation regions (Noël et al., 2015). Although for this example of SMB within CISM-A, the comparison is somewhat contrived to illustrate capability, SMB forcings can be monitored along with output variables to track their impact on the simulation.

Scatter plots comparing the same data are also displayed, whereby areas with close correspondence between the two datasets are clustered along the red identity line. As applied to CISM-A vs. RACMO2.3 for the SMB (Fig. 3), generally the differences between the model and RACMO2.3 surface mass balance values are small (as expected given the origin of the SMB forcing data).

LIVVkit also presents contour figures for the GrIS climatology of top-level temperature (without comparison data; not shown), and velocity $L^{2}$ norm for a stand-alone model. The norms are created for the entire GrIS and several regions of interest, which are those that highlight the Jakobshavn, Zachariae, and Petermann glaciers. Figure 4 is focused around drainage basins 7 and 8 (see Fig. 1 for reference) to include the Jakobshavn glacier.

\subsection{Coupled-model analysis}

Land ice behavior is critically dependent on various forcings from the atmosphere and land surface, so analyses of these fields within a coupled model comprise a significant portion of LIVVkit validation. LIVVkit also targets the land ice component within a coupled simulation using the same analysis procedures described in Sect. 4.1 for a stand-alone land ice model, if that component is active. As with the standalone analysis, LIVVkit presents area-averaged climatological fields in tabular form for a "quick look" overview applied to the CESM simulation and RACMO2.3 comparison data, as shown in Table 2. When applying the GrIS mask for averaging, the variables are multiplied by the percent of grid cell that is land ice, which is constant for the CESM simulation. Within the land model component, the downwelling and net shortwave $\left(\mathrm{SW}_{\mathrm{d}}\right.$ and $\left.\mathrm{SW}_{\text {net }}\right)$ and longwave $\left(\mathrm{LW}_{\mathrm{d}}\right.$ and $\left.\mathrm{LW}_{\text {net }}\right)$ radiation, respectively, the net surface radiation, $R_{\text {net }}$, the turbulent sensible and latent heat fluxes (SHFs and LHFs), and the SMB are all summarized. From the atmosphere component, the $2 \mathrm{~m}$ air temperature (T2m) is presented. Here, LIVVkit produces identical results for CESM output as in V13 except for the SMB, because LIVVkit uses monthly averaged values of the ice growth/melt (QICE) field.

The variables summarized in Table 2 are also presented as contour plots over GrIS to highlight regional differences from RACMO2.3. Annualized and/or seasonal fields (as appropriate) from land surface and atmosphere are provided for the model, RACMO2.3, and the difference, where RACMO2.3 is interpolated to the CESM grid. The summer LW $_{\text {net }}$ in CESM is presented in Fig. 5 as an example and shows that although the model is able to capture the general spatial variation and minimum values near the NE coast, there are overly large values (less heat loss) near the center of the land ice.

Contour and scatter plots of climatological atmospheric $2 \mathrm{~m}$ height temperature are also provided for polar summer 
(a) CISM-A

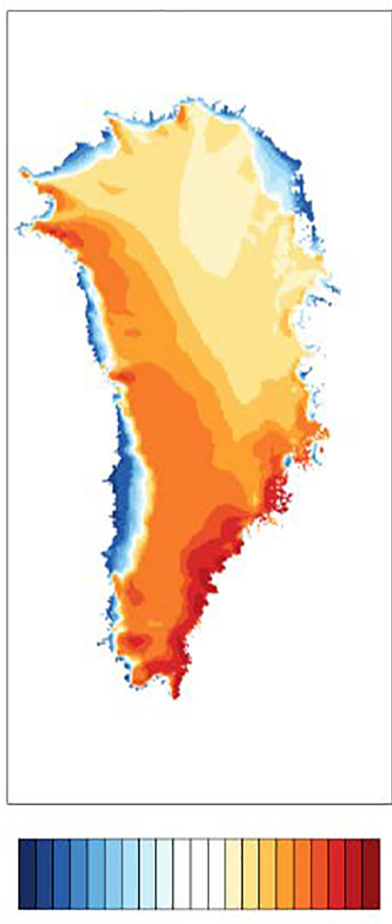

$\begin{array}{rrrrrr}2000 & -500 & -100 & 20 & 200 \quad 700 \quad 5000\end{array}$ (b) RACMO23

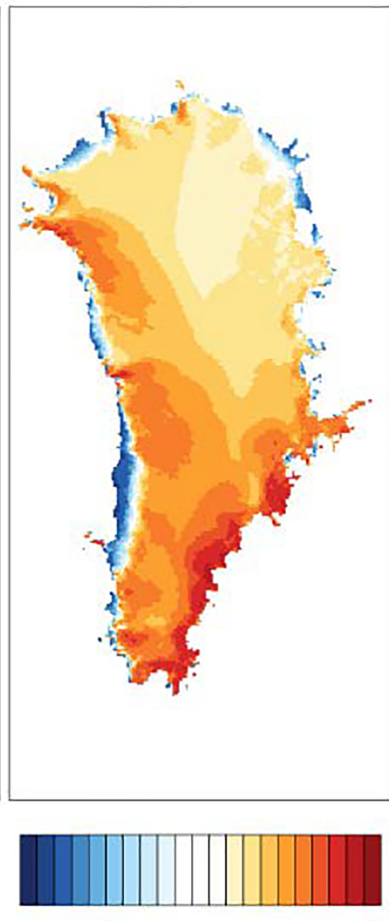

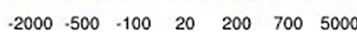

(c) CISM-A-RACMO23

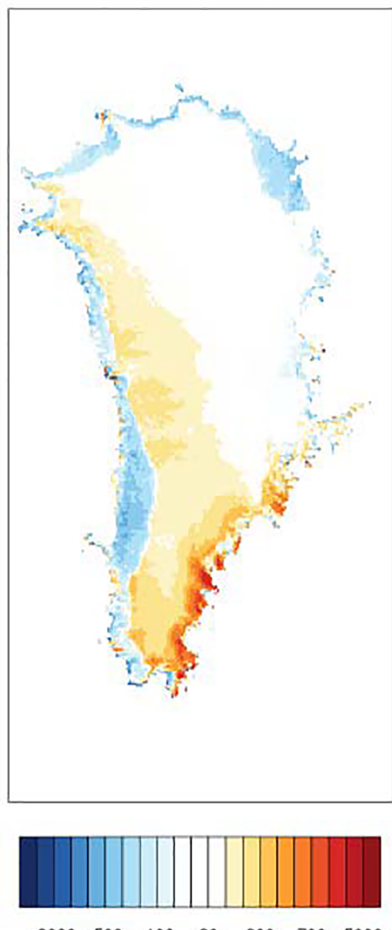

$\begin{array}{rrrrrr}.2000 & -500 & -100 \quad 20 \quad 200 \quad 700 & 5000\end{array}$

Figure 2. Surface mass balance contours for (a) CISM-A forced with RACMO2.0, (b) RACMO2.3, and (c) CISM-A minus RACMO2.3, with CISM-A interpolated to the coarser RACMO2.3 grid.

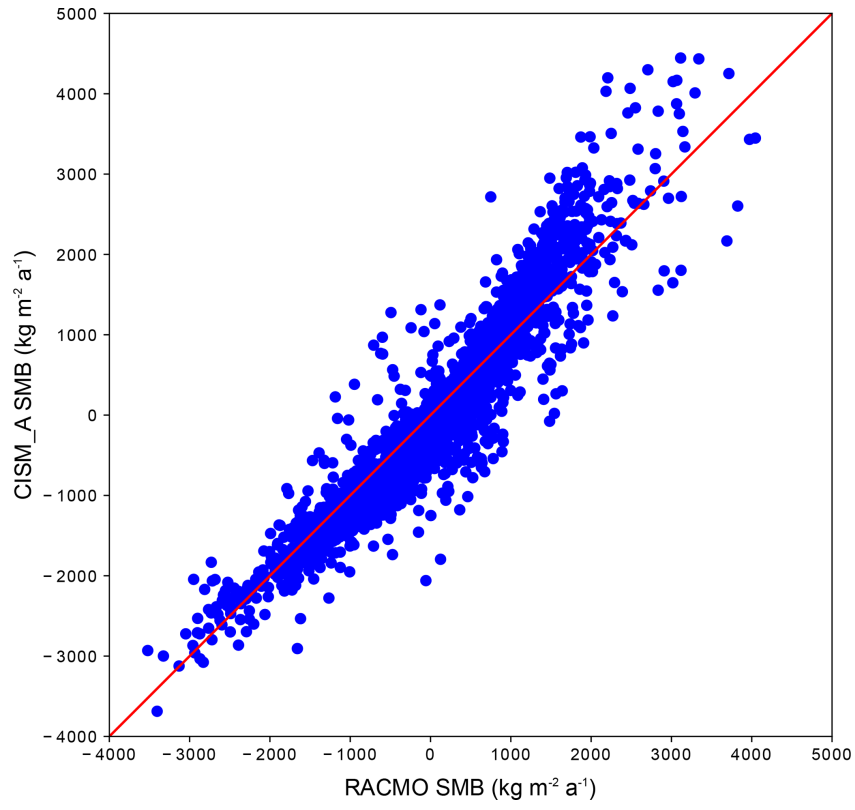

Figure 3. Scatter plot of all grid points of SMB for RACMO2.3 vs. CISM-A interpolated to the RACMO2.3 grid.
Table 2. Area-weighted and GrIS-masked climatologies for a host of key land surface variables from CESM's land surface and atmosphere components for summer (JJA), except SMB, which is an annual climatology, compared to RACMO2.3 values. All variables are in $\mathrm{W} \mathrm{m}^{-2}$ except SMB $\left(\mathrm{kg} \mathrm{m}^{-2} \mathrm{a}^{-1}\right)$ and $\mathrm{T} 2 \mathrm{~m}\left({ }^{\circ} \mathrm{C}\right)$.

\begin{tabular}{lrr}
\hline Data & CESM & RACMO2.3 \\
\hline SW $_{\mathrm{d}}$ & 268 & 301 \\
SW $_{\text {net }}$ & 61 & 58 \\
LW $_{\mathrm{d}}$ & 235 & 224 \\
LW $_{\text {net }}$ & -46 & -52 \\
$R_{\text {net }}$ & 15 & 5.5 \\
SHF & 7 & 8 \\
LHF & -8 & -6 \\
SMB & 209 & 238 \\
T2m & -20.6 & -21.9 \\
\hline
\end{tabular}

(JJA) and winter (DJF) in LIVVkit; a contour plot for JJA is shown in Fig. 6. The near-surface temperature is critical to track in a coupled model because it drives the processes of surface melt and refreezing.

The representation of clouds over GrIS in the coupled model is also evaluated in LIVVkit because they contribute to the surface energy budget and related processes such as surface melting and refreezing (Van Tricht et al., 2016). The comparisons provided by LIVVkit include the annual cycle 
(a) Init

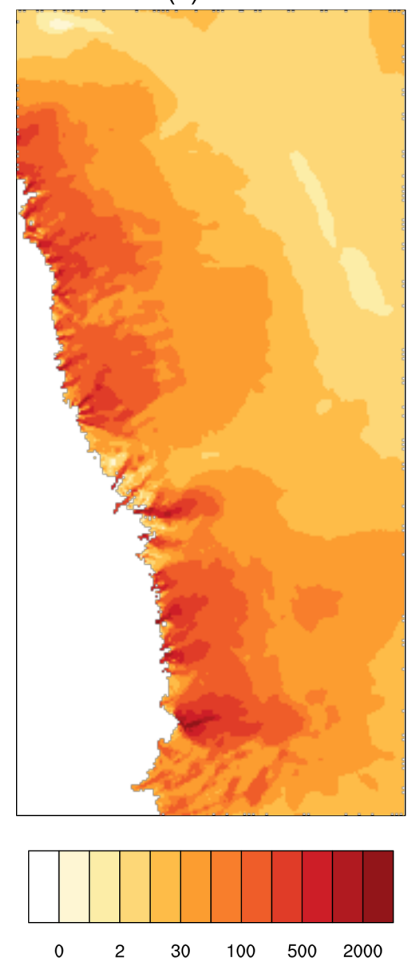

(b) CISM-A

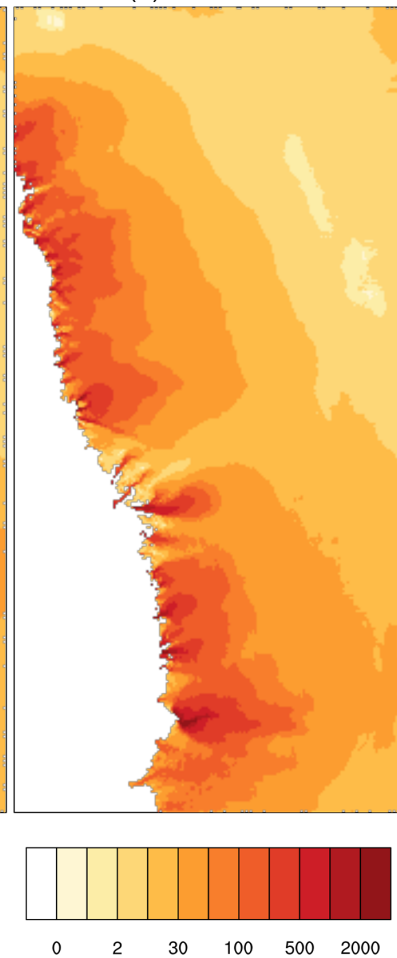

(c) CISM-A - Init

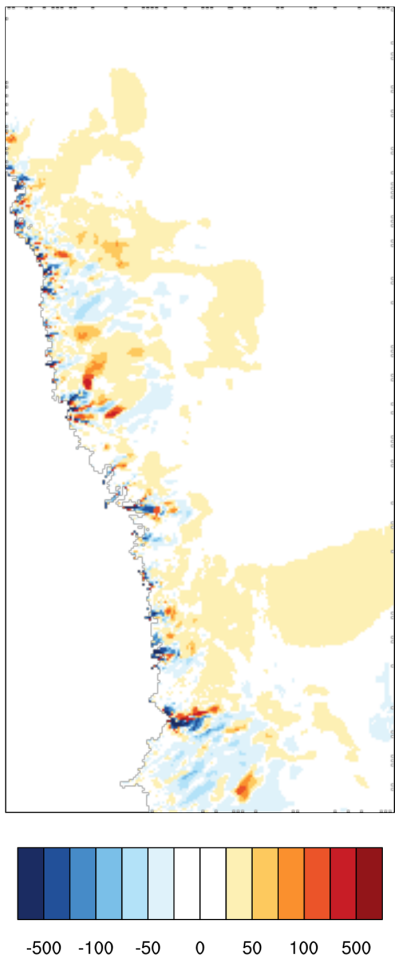

Figure 4. The norm of the surface velocity field ( $\mathrm{m} \mathrm{s}^{-1}$, given by the color bars) from initialization (Joughin et al., 2010a, b) (a), CISM-A (b), and the difference (c) over drainage basins 7 and 8 as indicated by Fig. 1.
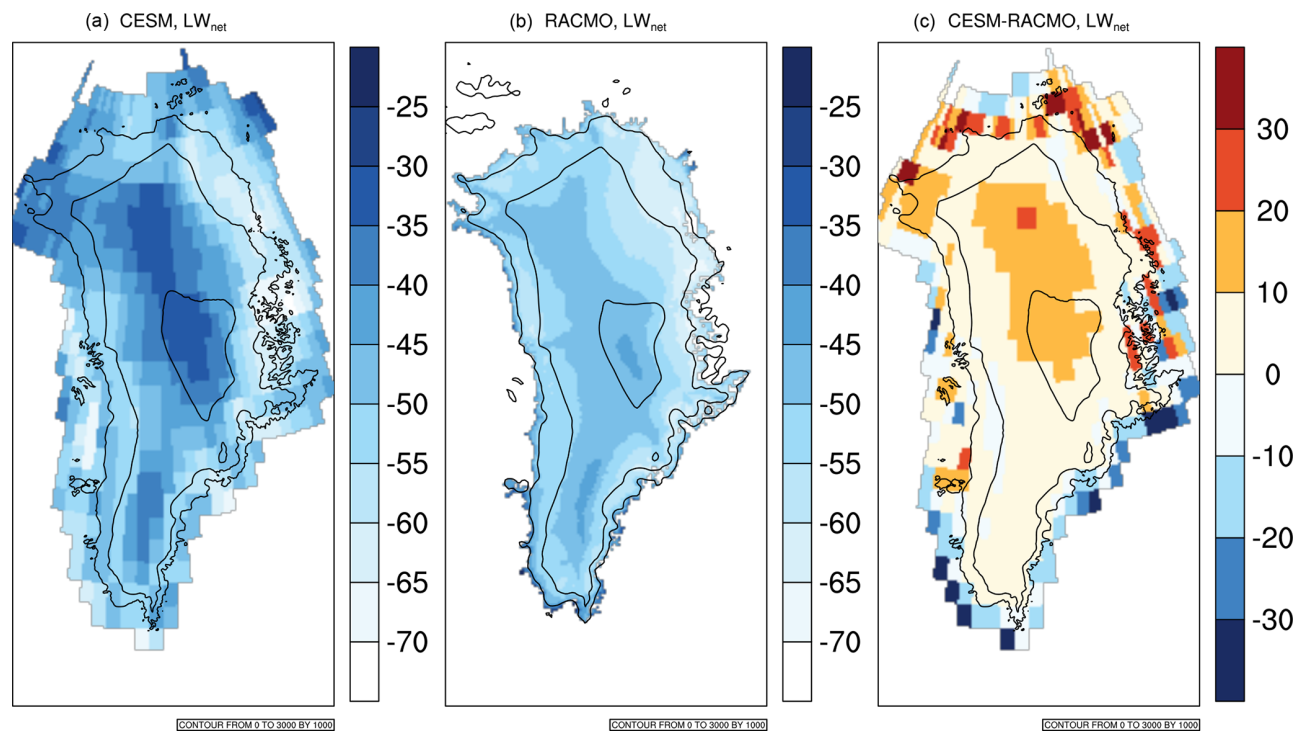

Figure 5. Summer net longwave radiation $\left(\mathrm{W} \mathrm{m}^{-2}\right.$ ) for CESM (a), RACMO2.3 (b), and the difference (c). The black solid lines denote elevation at 0, 1000, 2000, and $3000 \mathrm{~km}$ levels in each grid. The CESM elevation (b, c) uses the $5 \mathrm{~km}$ downscaled values.

of monthly averaged low, high, and total clouds for both the model and ISCCP and CLOUDSAT observationally derived datasets and contour plots of annual and seasonal averages of low, high, and total cloud amount. For the annual cycles, the data are area averaged over the GrIS region for each month of the climatology. Several examples of the cloud analysis as applied to CESM are displayed in Figs. 7 and 8. The ISCCP and CLOUDSAT monthly averages over GrIS in Fig. 7 exhibit a seasonal cycle, which is consistent with findings over the entire Arctic (Chernokulsky and Mokhov, 2012). 

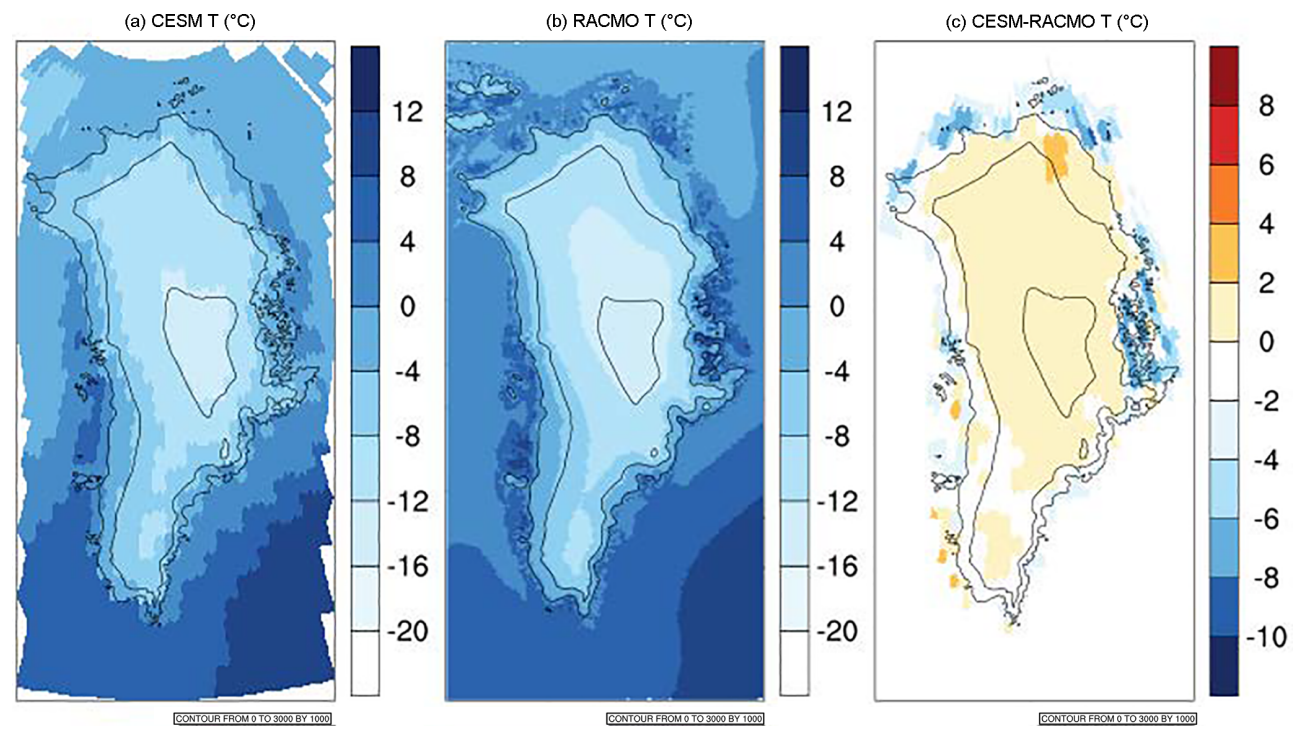

Figure 6. Averages for the JJA season of surface temperature over the GrIS for CESM (a), RACMO2.3 (b), and CESM-RACMO2.3 (c). Elevation contours are as in Fig. 5.

However, the CESM produces total clouds that are considerably too few and capture no summer minimum, also consistent with noted CESM biases observed for the whole Arctic region (Barton et al., 2012). This bias is not universal for all cloud levels; Fig. 8 shows that the annual values of low clouds more closely match CLOUDSAT than ISCCP (although the seasonal cycle is opposite that from observations, with a summer maximum; not shown). These plots indicate the need for a deeper investigation. Recent efforts to understand the limitations of both models and observed and reanalysis datasets in representing clouds over the Arctic (e.g., Chernokulsky and Mokhov, 2012; Lenaerts et al., 2012), and focused over Greenland (Hofer et al., 2017), provide a good starting point.

Similar to Fig. 2 for CISM-A, LIVVkit produces a contour plot of ice-sheet-wide SMB compared to RACMO2.3 (not shown). For the coupled simulation, a times series for the area-averaged values over GrIS covering the entire range of a simulation is provided by LIVVkit, as in Fig. 9 for CESM. The values are calculated with the same methodology as with the SMB in Table 2, except for the time averaging.

To break down climatological behavior of the time series and quantify the variability, a box plot of the SMB time series is provided, as shown in Fig. 10 for CESM and RACMO2.3. In this plot, the rectangle spans the $25 \%$ quartile to the $75 \%$ quartile (the interquartile range, or IQR) of the time series with the median shown as the red line in the rectangle. The two whiskers represent $1.5 \times \mathrm{IQR}$ above the $75 \%$ quartile and below the $25 \%$ quartile, respectively. The diamonds outside the whiskers are suspected outliers. In Fig. 9, the extent of the whiskers is similar for CESM and RACMO23, so the model data have similar variability compared to RACMO2.3. However, the slightly smaller and

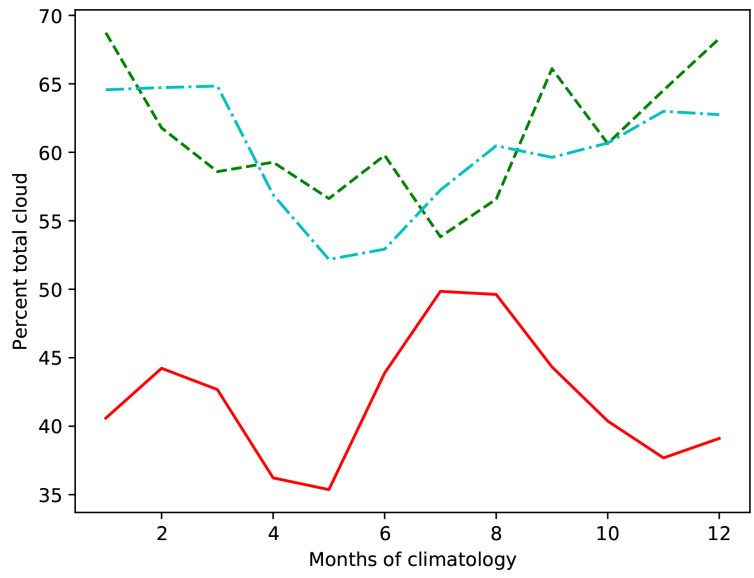

Figure 7. Climatological monthly averages of total clouds over the GrIS region for CESM (red), ISCCP (Rossow and Schiffer, 1999) (green), and CLOUDSAT (Kay and Gettelman, 2009) (cyan).

lower IQR box for the RACMO2.3 data indicates that its data are slightly less variable and skewed low. Given the smaller dataset size of RACMO2.3, this result is not surprising.

\subsection{Basin scale SMB analysis}

The increasing availability of SMB observational data outlined in Sect. 2 presents an opportunity to delve into the quality of simulated SMB. With this in mind, LIVVkit provides analyses of the SMB by basin and elevation using these data, applied here to the CESM SMB values that have been downscaled to $5 \mathrm{~km}$ within the land ice component. A LIVVkit contour plot of the CESM SMB, overlain by circles representing the observed data locations (as in Fig. 1), is shown in 
(a) CESM

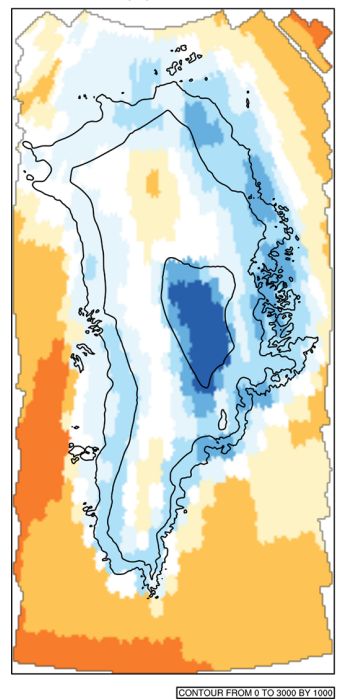

(b) ISCCP

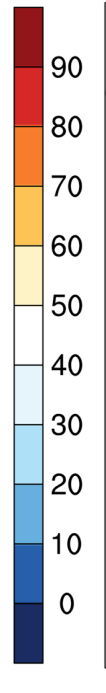

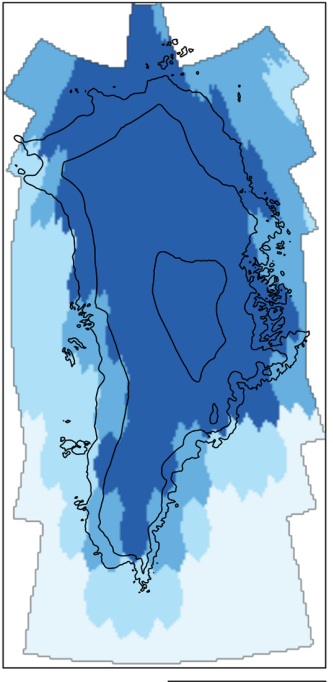

(c) CLOUDSAT

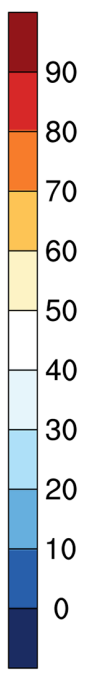

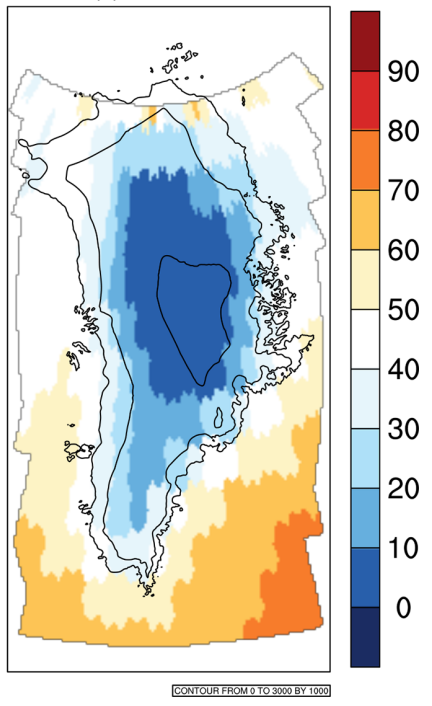

Figure 8. Climatological annual average of low clouds (\%) over the GrIS for CESM (a), ISCCP (Rossow and Schiffer, 1999) (b), and CLOUDSAT (Kay and Gettelman, 2009) (c). The downscaled CESM values are used for all elevation contours.

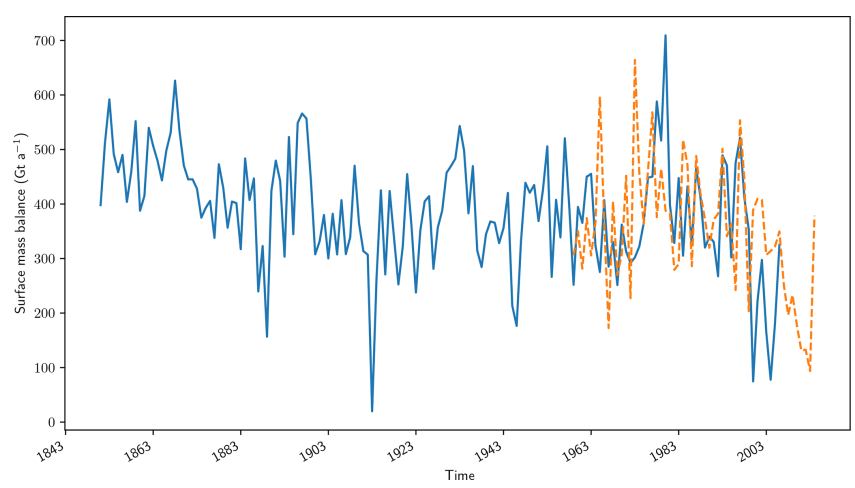

Figure 9. Times series of the (blue) CESM surface mass balance for the entire simulation, 1851-2006, compared to the (orange) RACMO 2.3 surface mass balance.

Fig. 11. This figure is similar to Fig. 7 of V13 but includes more recently available data. The colors within the circles represent SMB estimates based on snow pit and/or firn/ice core studies.

To provide more quantitative comparisons, these data are also presented as a histogram of differences between modeled and observed annual surface mass balance values at pit/core locations where data exist. It is shown for the entire GrIS in Fig. 12 and for each of the eight basins delineated in Figs. 1 and 13. Observational data for Figs. 12 and 13 were compiled and processed by LIVVkit from the pit/core data as described in Sect. 2. The vertical light blue line denotes the 0 difference line for model vs. observed data; values above (below) this line indicate that the model overestimates (underestimates) SMB in comparison to altimetry observations. High frequencies near zero imply greater model agreement.

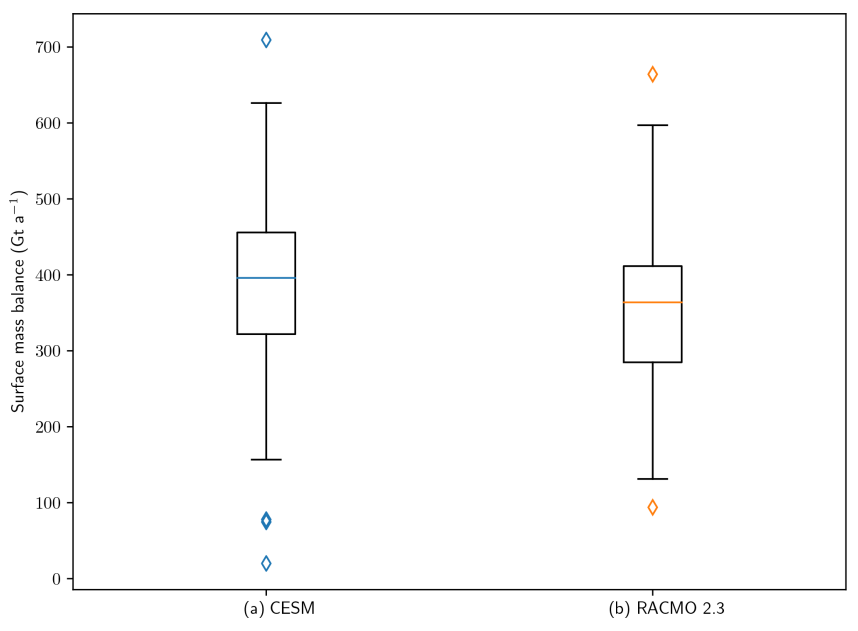

Figure 10. Box plot of (a) CESM annual surface mass balance for the entire simulation, 1851-2006, compared to the (b) RACMO 2.3 annual surface mass balance for 1961-2013. The diamonds represent extreme values within the series as explained in the text.

Note that because this plot compares nearest-neighbor values without any spatial interpolation, one coarse model cell may be compared to multiple (if not many) observed SMB estimates, because the data collection sites are often located in clusters. The correspondence of model to observational data varies significantly by basin and shows better agreement in the central latitude regions as compared to the southern and northern regions. V13 showed lower values of SMB over region 4 for CESM relative to RACMO2.0, but in fact CESM is rather close to observations in this region. Consistent with this, RACMO version 2.3 exhibits a significant decrease in 


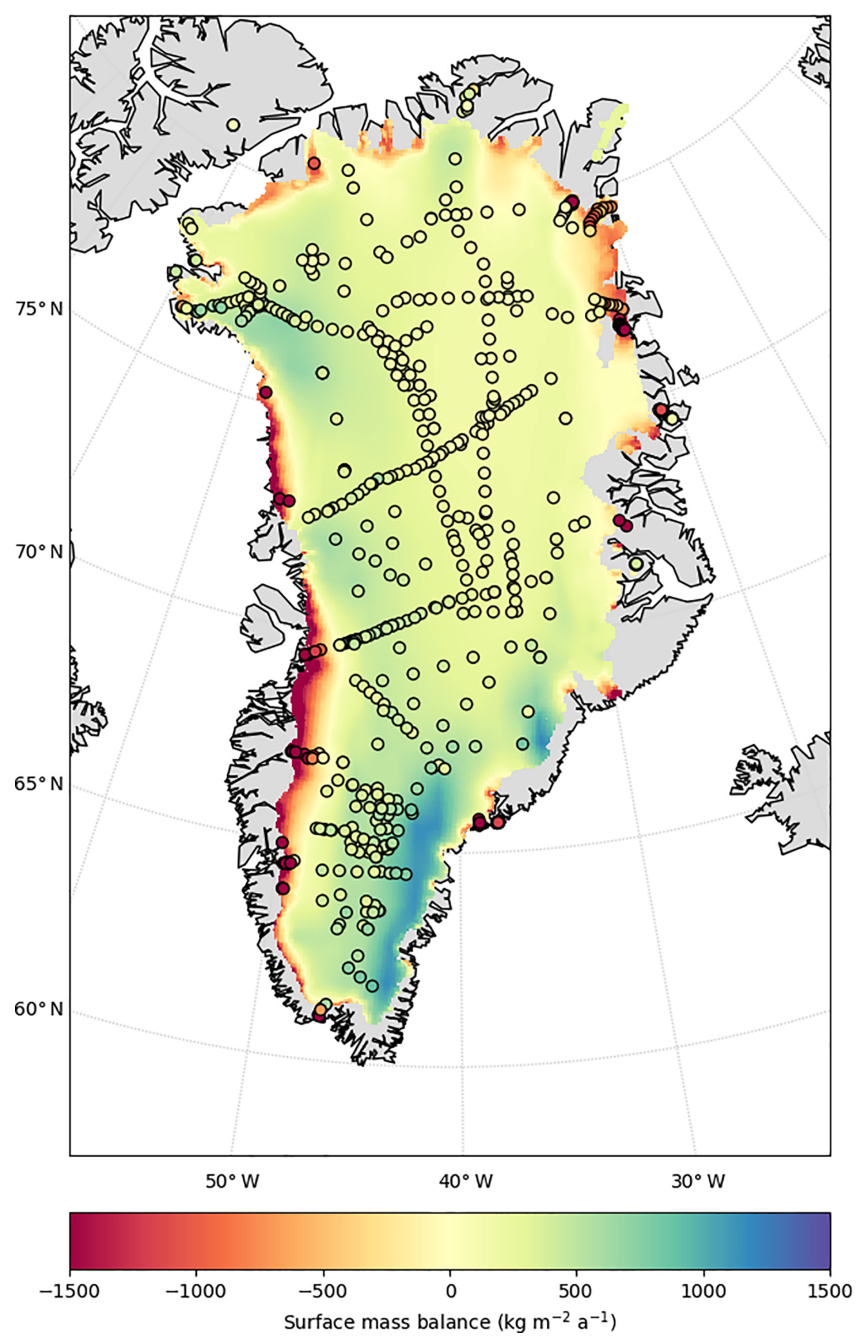

Figure 11. Filled contours of the annual SMB of the Greenland land ice as modeled by CESM, with pit/core field estimates overlaid as filled circles. Data were compiled as detailed in Sect. 2 from both ablation and accumulation zones.

precipitation (Noël et al., 2015), apparently bringing its SMB closer to observations. LIVVkit also provides plots similar to those in Figs. 12 and 13 but with comparison to the IceBridge data.

Scatter plots comparing CESM to the SMB estimates from pit/core data and IceBridge areal estimates, separating accumulation and ablation zones and colored by basin, are also provided by LIVVkit. Figure 14, which shows pit/core data, demonstrates that CESM is currently not able to capture the SMB well in the ablation areas of basin 6 (gray, the southwest GrIS). Figure 13 shows this bias as well. Separating ablation from accumulation provides the source of bias: the overly positive SMB in region 6, and overall, is due to too little ablation relative to observations, not too much accumulation.

While SMB comparisons by basin are helpful, model biases in elevation can provide clues as to the source. Figure 15

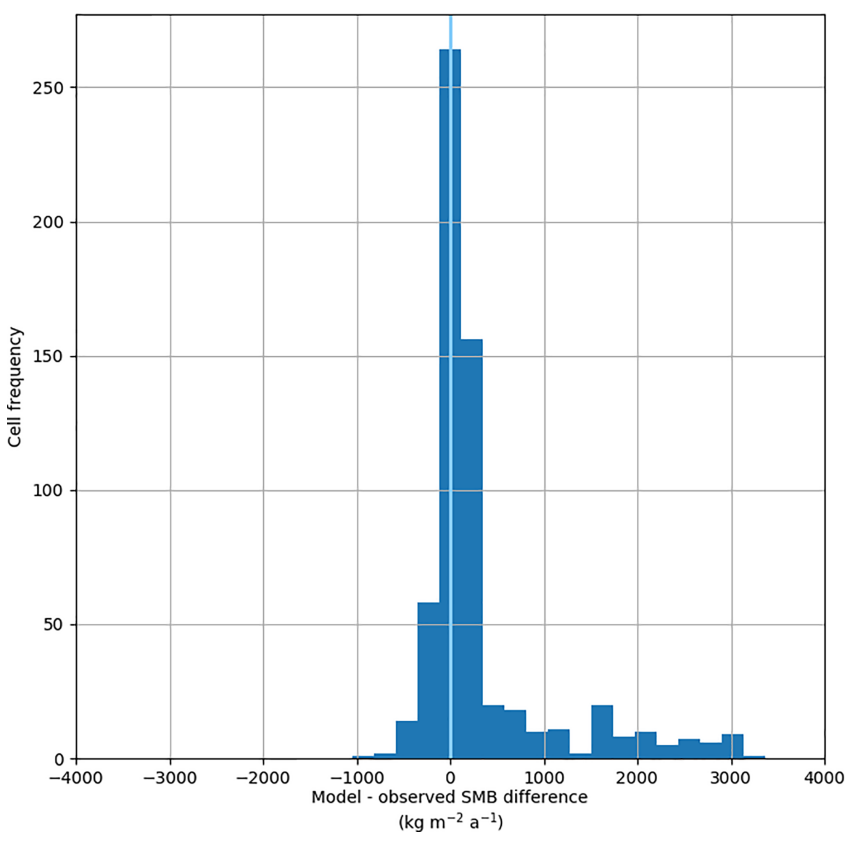

Figure 12. Histogram of differences between modeled and observed annual SMB, at all collected pit/core locations as detailed in Sect. 2 from ablation and accumulation zones. The light blue line highlights 0 difference between model and observed; values above (below) this line indicate that the model overestimates (underestimates) SMB in comparison to the observations.

presents CESM and observed SMB over accumulation and ablation regions vs. their elevation, and colored by basin, so that model developers are able to identify areas where there is an elevation mismatch. Because the model and observed data are not co-located, their horizontal locations are different. The observed data show a strong positive linear relationship between SMB and elevation up to about $1500 \mathrm{~m}$, above which almost all points (except several in basin 1) have a positive SMB. The model is also able to capture this characteristic; however, the linear relationship is more diffuse, and the linear increase in ablation with decreasing elevation is too weak in CESM in basin 6 of the GrIS. Referring back to Fig. 6, the temperature gradient from the higher central part of GrIS to the edges is slightly weaker in CESM than RACMO2.3 in summer (and even more so in winter; not shown), with colder temperatures at the edges, which is consistent with the slope of elevation vs. SMB shown in Fig. 15.

LIVVkit breaks down the model vs. elevation data comparison along several key transects in the ablation zone, and Fig. 16 shows that for CESM, all four transects contain some mismatch, but the Qammanarssup Sermia and Kangerlussuaq (K) transects (basin 6) echo the overly weak modeled slope of elevation vs. SMB ablation as seen in Fig. 15. As for the accumulation zone, LIVVkit's processed IceBridge transect data are presented as contours by location in the GrIS along with model vs. observed data in Fig. 17. The CESM 

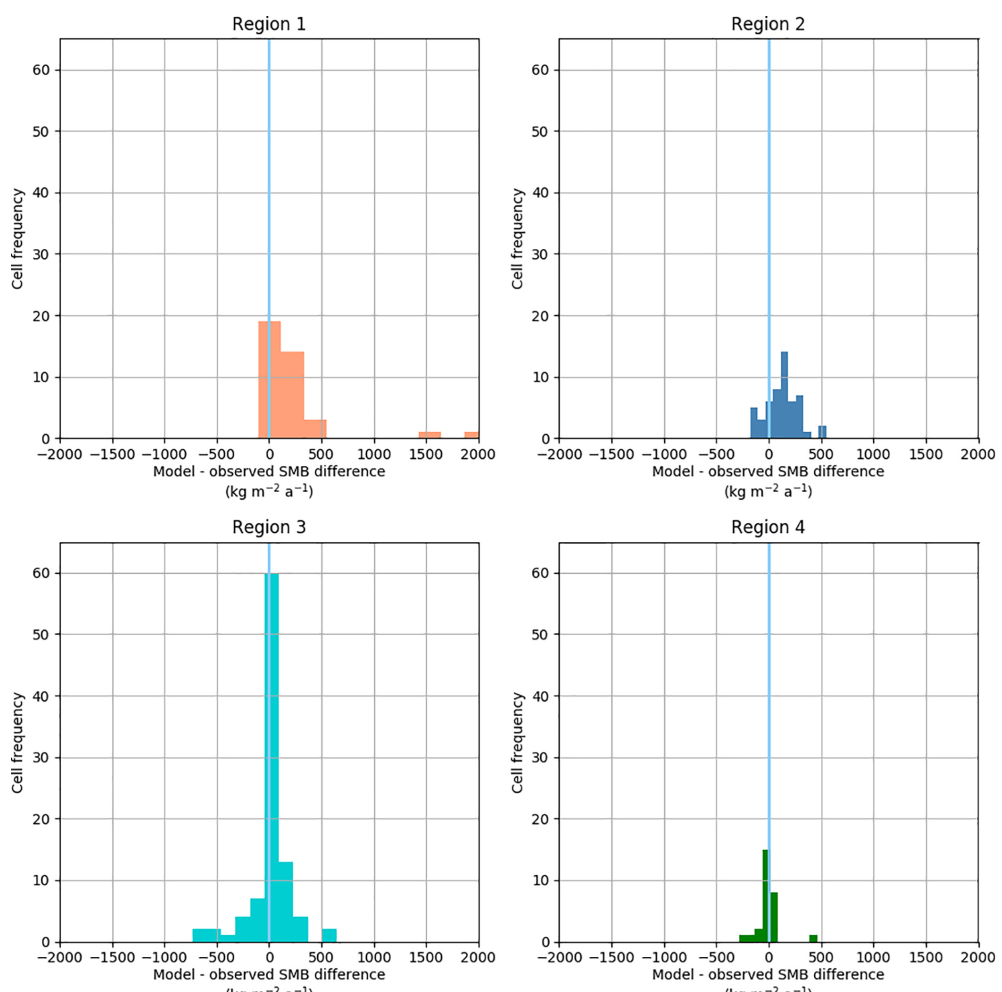

$\left(\mathrm{kg} \mathrm{m}^{-2} \mathrm{a}^{-1}\right)$
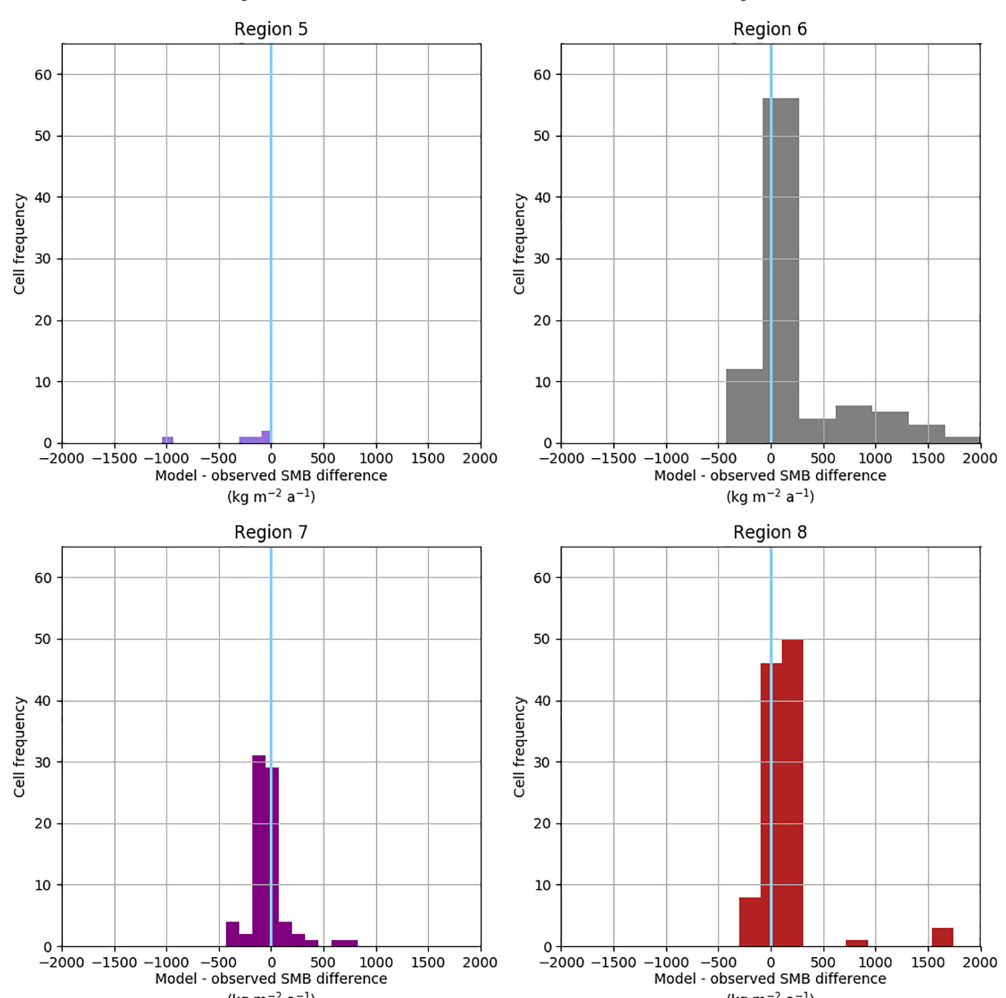
$\left(\mathrm{kg} \mathrm{m}^{-2} \mathrm{a}^{-1}\right)$ $\left(\mathrm{kg} \mathrm{m}^{-2} \mathrm{a}^{-1}\right)$

Figure 13. As in Fig. 12 but broken down into basins as marked in Fig. 1. Axes have been normalized for the eight drainage histograms to highlight differences between the number of comparison points per basin. 

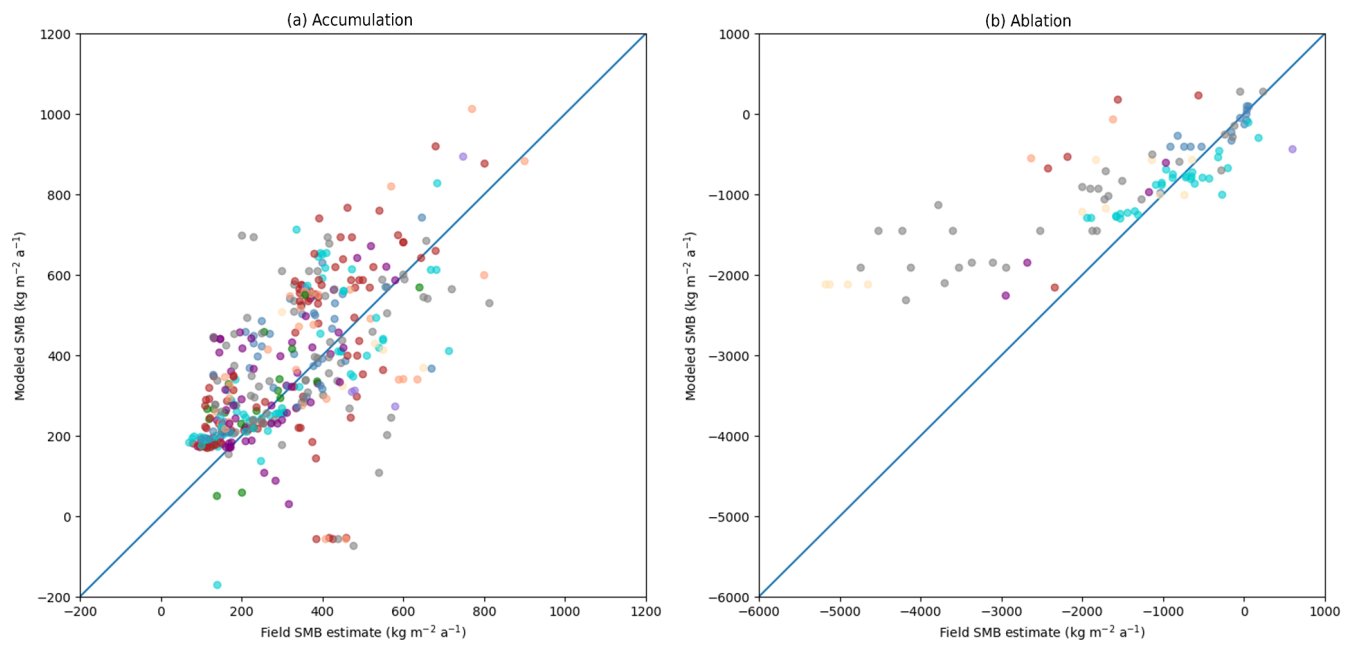

Figure 14. CESM annual SMB vs. observed estimates at locations taken from accumulation (a) and ablation zones (b). Observational data were compiled as detailed in Sect. 2. In both figures, colors correspond to the eight major drainage basins, as shown in Fig. 1, and the $1: 1$ line is drawn in blue.
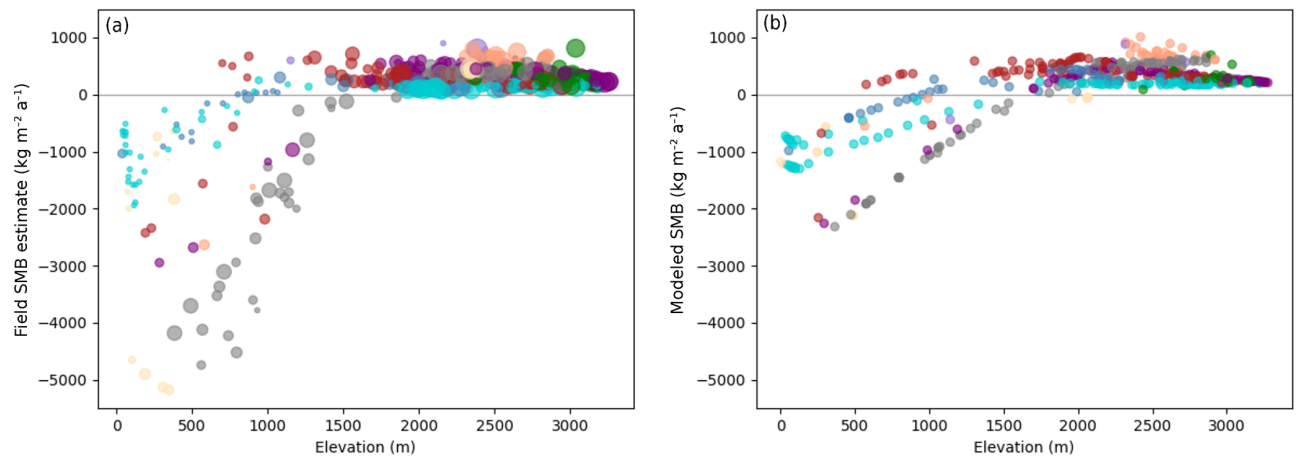

Figure 15. Field estimates of annual SMB as a function of observed elevation (a) and CESM annual SMB as a function of model elevation (b) from both accumulation and ablation zones. For the observed data, the size of the point represents the number of years in the field record, with larger points containing comparatively more temporal information than smaller points, and each point represents an annual surface mass balance estimate averaged across at least 1 year of data. For the modeled data, each point represents a model cell containing an available field estimate location. In both figures, colors correspond to the drainage basins as shown in Fig. 1.

bias has a latitudinal gradient; SMB is overestimated (e.g., basin 2) compared to annual IceBridge estimates in the northern half of the GrIS and the bias decreases going south, becoming too low relative to the observed data in the southern half. The source of this bias could be analyzed within the context of temperature, cloud cover, precipitation, and latent and sensible heat fluxes using figures such as Figs. 8 and 5, but covering the relevant seasons, but that is beyond the scope of this survey.

\section{Conclusions}

An initial capability to perform automated validation of land ice and coupled models is presented, and we encourage the land ice modeling and larger computational Earth sciences community to bring additional tools and analysis to improve the software from this baseline. For example, generalization of the software to use with other models and the inclusion of more data are top priorities. Although LIVVkit targets some aspects of relevant variables that affect land ice models within the coupled Earth system model as detailed above, there are additional analyses that could deliver useful information for both model developers and analysts. One example is to provide seasonal and long-term SMB trends for information about model stability and forcings. Specifically, seasonal (summer) SMB estimates relative to the PROMICE dataset, which we currently only show as annualized values, could be extended. Extensions to assess the Antarctic ice sheet (AIS) are also greatly needed and are a near-term priority. The recent release of Quantarctica, version $3^{2}$, pro-

\footnotetext{
${ }^{2}$ https://www.pgc.umn.edu/news/ quantarctica-version-3-released/, last access: 5 March 2019
} 

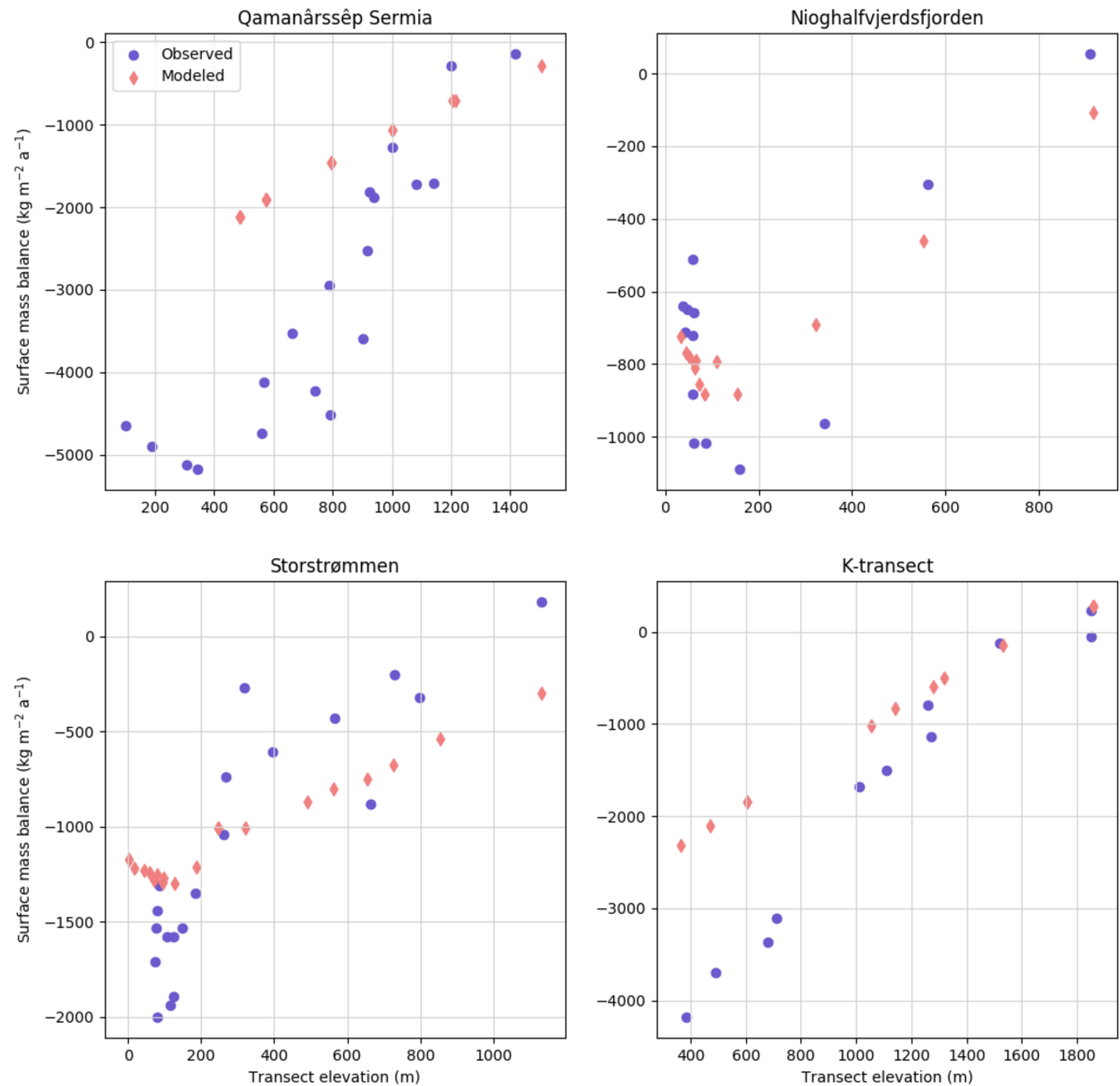

Figure 16. Annual surface mass balance as a function of observed elevation at four different areas in the ablation zone of GrIS. Red dots are modeled SMB and elevation, while blue dots are observed SMB and elevation from pit/core field estimates. Observational data were compiled from the PROMICE database (Machguth et al., 2016).

vides a collection of ice cores to consider for inclusion in LIVVkit.

Beyond new capabilities, additional observational data from both current and new sources would provide more information and build model confidence, for example, the Landsat 8 GoLIVE global ice velocity data derived from Landsat $8^{3}$ with $300 \mathrm{~m}$ spacing, error and quality parameters, and subannual, and in some cases monthly or less, time periods. A recent synthesis of modeled and remotely sensed inferences of the basal thermal state of GrIS (MacGregor et al., 2016) would provide a starting point for comparison temperature data. Additional SMB data to consider include data values from Airborne SAR/Interferometric Radar Altimeter System (ASIRAS) airborne radar and neutron-probe density measurements (Overly et al., 2016) and longer records from specific regions to better analyze time series behavior, e.g., van de Wal et al. (2012). Machguth et al. (2016) provide a history of SMB observations as a "state of the art" that can be used as a baseline for extension. Another source for additional SMB data, the Surface Mass Balance and Snow on Sea

\footnotetext{
${ }^{3}$ https://nsidc.org/data/golive, last access: 5 March 2019
}

Ice Working Group (SUMup, 2018), compiles flights and ice snow pit/ice core data that include PARCA cores which were included in LIVVkit as mentioned above, as well as aerial flights from both Greenland and Antarctica. The IceBridge dataset also included in LIVVkit uses the more recent 20132014 flights; however, earlier flights as detailed in Koenig et al. (2016) would provide more comparison within the ablation zone.

Next steps for LIVVkit being pursued include a connection to the $\mathrm{CmCt}$ validation framework that compares ice sheet models to altimetry and gravimetry satellite observations from the Ice, Cloud, and land Elevation Satellite (ICESat) and Gravity Recovery and Climate Experiment (GRACE) (Price et al., 2017). The substantial postprocessing required to compare the model with observations would complement the other metrics presented here, as an opt-in feature. Performance validation, which would expand from an initial computational verification capability as presented in Kennedy et al. (2017), is underway; the goals are to track model computational behavior on high-performance computers. Efforts to enable LIVVkit's kernels, the Extended V\&V 

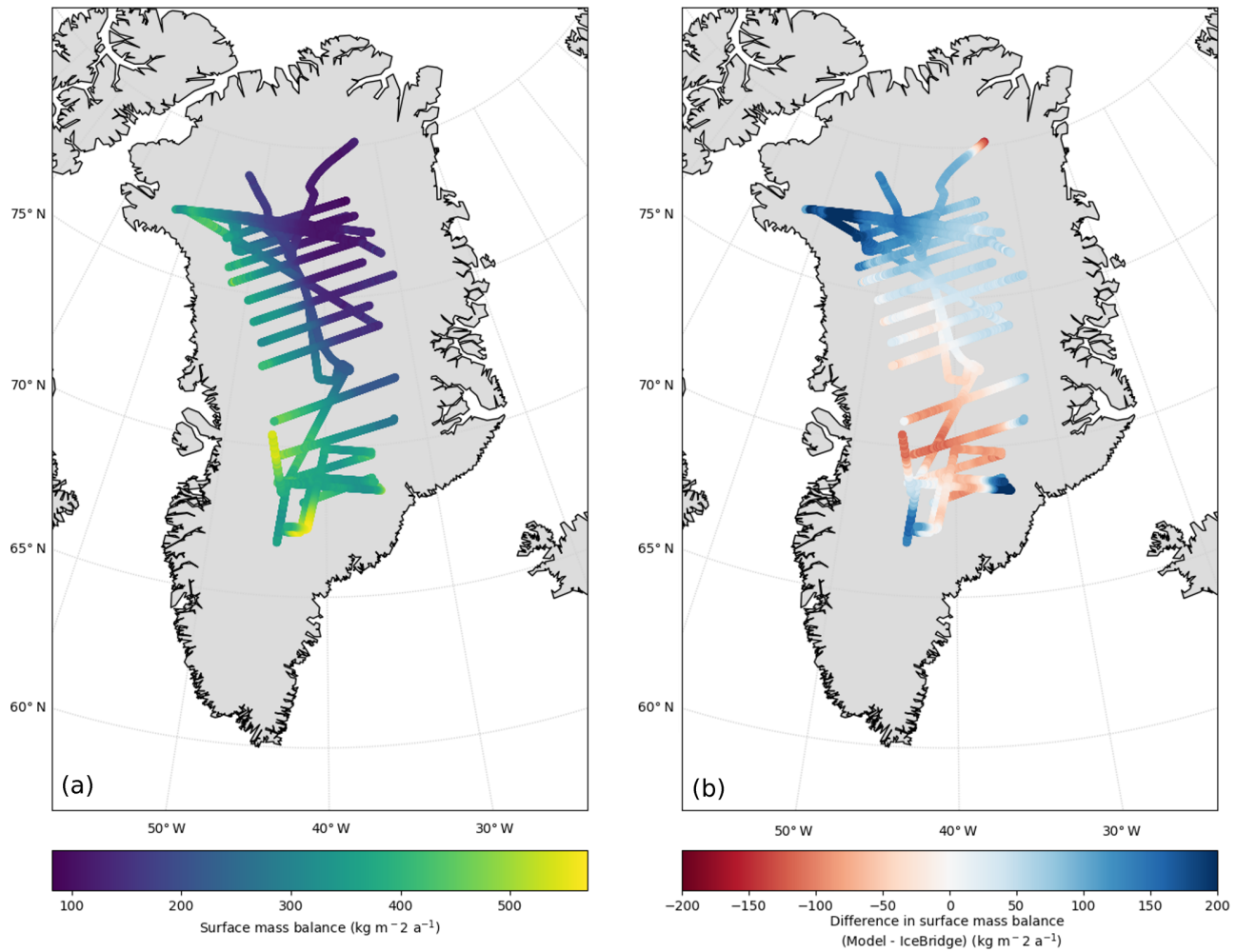

Figure 17. Observed annual surface mass balance of GrIS along IceBridge altimetry transects (a) and the differences between the observations and model along the transects (b).

for Earth Systems (EVE), to handle ensembles of output and provide sensitivities of variables to perturbed initial conditions are also being pursued, targeting verification using short ensembles of climate model configurations (e.g., Mahajan et al., 2017). Future work to develop and deploy uncertainty quantification techniques using LIVVkit within a larger ensemble-based workflow would enable more robust uncertainty information regarding climate projections.

Several challenges exist in deploying LIVVkit for largescale multimodel validation. There are several efforts we recommend for improved verification and validation in general, and to make LIVVkit more robust and extensible. Using common model projections and data conventions would allow many different models to participate in LIVVkit postprocessing with minimal code changes and other related information such as external mask and areal information, etc. Some accepted protocol should be developed for LIVVkit to postprocess the data automatically. The land ice community is a relative newcomer within the coupled Earth system model community, so adoption of already accepted formats in use by other components would facilitate this transition. In any case, the breadth of ice sheet model development has created an opportunity to provide critically important simulations to the climate community, and this validation package is a step toward a predictive capability for land ice models, both on their own and coupled to a global Earth system model.
Code and data availability. The LIVVkit version 2.1 source code and documentation (Kennedy et al., 2018a) are available via a modified BSD license at https://github.com/LIVVkit/LIVVkit (last access: 5 March 2019) and https://livvkit.github.io/Docs (last access: 5 March 2019), respectively. The reader can access all the datasets and reproduce all the analyses presented here with LEX (Kennedy et al., 2018b), which is available via a modified BSD license at https://code.ornl.gov/LIVVkit/lex (last access: 5 March 2019) and is documented in the LIVVkit documentation. More details about data and code access are provided in Sects. 2 and 3, respectively.

Author contributions. KJE wrote most of the paper and performed some of the postprocessing. JHK led the software strategy and development of LIVVkit and other related repositories, and performed some of the postprocessing and visualization. MMF collected the SMB data and performed the basin SMB postprocessing. DL and $\mathrm{AB}$ wrote some postprocessing and LIVVkit code. SP and $\mathrm{MH}$ advised on the appropriate ice sheet metrics. JF, MV, and IT advised on and provided example target model data and advised on appropriate metrics. CZ developed NCO for LIVVkit needs and advised on postprocessing. All authors edited the manuscript.

Competing interests. The authors declare that they have no conflict of interest. 
Acknowledgements. Support for this work was provided through Scientific Discovery through Advanced Computing (SciDAC) program funded by the US Department of Energy Office of Advanced Scientific Computing Research and Office of Biological and Environmental Research. This paper has been authored by UT-Battelle, LLC and used resources of the National Center for Computational Sciences at Oak Ridge National Laboratory, both of which are supported by the Office of Science of the US Department of Energy under contract no. DE-AC05-00OR22725. Contributions of Charles S. Zender were made possible by support from DOE E3SM DE-SC0012998 and NASA ACCESS NNX14AH55A. Miren Vizcaíno acknowledges support the European Research Council ERC-StG-678145-CoupledIceClim. The United States Government retains and the publisher, by accepting the article for publication, acknowledges that the United States Government retains a non-exclusive, paid-up, irrevocable, world-wide license to publish or reproduce the published form of this paper, or allow others to do so, for United States Government purposes.

Edited by: Didier Roche

Reviewed by: two anonymous referees

\section{References}

Aschwanden, A., Fahnestock, M. A., and Truffer, M.: Complex Greenland outlet glacier flow captured, Nat. Commun., 7, 10524, https://doi.org/10.1038/ncomms10524, 2016.

Bales, R. C., McConnell, J. R., Mosley-Thompson, E., and Csatho, B.: Accumulation over the Greenland ice sheet from historical and recent records, J. Geophys. Res., 106, 33813-33825, 2001.

Bales, R. C., Guo, Q., McConnell, J. R., Du, G., Burkhart, J., Spikes, V., Hanna, E., and Cappelen, J.: Annual accumulation for Greenland updated using ice core data developed during 2000-2006 and analysis of daily coastal meteorological data, J. Geophys. Res., 114, D06116, https://doi.org/10.1029/2008JD011208, 2009.

Barbi, D., Lohmann, G., Grosfeld, K., and Thoma, M.: Ice sheet dynamics within an earth system model: downscaling, coupling and first results, Geosci. Model Dev., 7, 2003-2013, https://doi.org/10.5194/gmd-7-2003-2014, 2014.

Barton, N. P., Klein, S. A., Boyle, J. S., and Zhang, Y. Y.: Arctic synoptic regimes: Comparing domain-wide Arctic cloud observations with CAM4 and CAM5 during similar dynamics, J. Geophys. Res., 117, D15205, https://doi.org/10.1029/2012JD017589, 2012.

CESM Software Engineering Group (CSEG): CESM 1.0.z User's Guide, available at: http://www.cesm.ucar.edu/models/cesm1.0/ cesm/cesm_doc_1_0_6/book1.html (last access: 5 March 2019), 2014.

Chernokulsky, A. and Mokhov, I. I.: Climatology of Total Cloudiness in the Arctic: An Intercomparison of Observations and Reanalyses, Adv. Meteorol., 542093, 1-15, https://doi.org/10.1155/2012/542093, 2012.

Church, J. A., Clark, P. U., Cazenave, A., Gregory, J. M., Jevrejeva, S., Levermann, A., Merrifield, M. A., Milne, G. A., Nerem, R. S., Nunn, P. D., Payne, A. J., Pfeffer, W. T., Stammer, D., and Unnikrishnan, A. S.: Sea Level Change, in: The Physical Science Basis. Contribution of Working Group I to the Fifth Assessment
Report of the Intergovernmental Panel on Climate Change, edited by: Stocker, T., Qin, D., Plattner, G.-K., Tignor, M., Allen, S., Boschung, J., Nauels, A., Xia, Y., Bex, V., and Midgley, P., p. 151, IPCC, Geneva, Switzerland, 2013.

Cogley, J. G.: Greenland Accumulation: An error model, J. Geophys. Res., 109, D18101, https://doi.org/10.1029/2003JD004449, 2004.

Dee, D. P., Uppala, S. M., Simmons, A. J., Berrisford, P., Poli, P., Kobayashi, S., Andrae, U., Balmaseda, M. A., Balsamo, G., Bauer, P., Bechtold, P., Beljaars, A. C. M., van de Berg, L., Bidlot, J., Bormann, N., Delsol, C., Dragani, R., Fuentes, M., Geer, A. J., Haimberger, L., Healy, S. B., Hersbach, H., Hólm, E. V., Isaksen, L., Kållberg, P., Köhler, M., Matricardi, M., McNally, A. P., Monge-Sanz, B. M., Morcrette, J.-J., Park, B.-K., Peubey, C., de Rosnay, P., Tavolato, C., Thépaut, J.-N., and Vitart, F.: The ERA-Interim reanalysis: Configuration and performance of the data assimilation system, Q. J. Roy. Meteor. Soc., 137, 597-597, https://doi.org/10.1002/qj.828, 2011.

Fettweis, X., Franco, B., Tedesco, M., van Angelen, J. H., Lenaerts, J. T. M., van den Broeke, M. R., and Gallée, H.: Estimating the Greenland ice sheet surface mass balance contribution to future sea level rise using the regional atmospheric climate model MAR, The Cryosphere, 7, 469-489, https://doi.org/10.5194/tc7-469-2013, 2013.

Gleckler, P.: The second phase of the Atmospheric Model Intercomparison Project (AMIP2): Toward Innovative model diagnostics, in: WCRP/WGNE Workshop, Meteo-France, Toulouse, France, 11-14 November 2002, 2004.

Goelzer, H., Nowicki, S., Edwards, T., Beckley, M., Abe-Ouchi, A., Aschwanden, A., Calov, R., Gagliardini, O., Gillet-Chaulet, F., Golledge, N. R., Gregory, J., Greve, R., Humbert, A., Huybrechts, P., Kennedy, J. H., Larour, E., Lipscomb, W. H., Le clec'h, S., Lee, V., Morlighem, M., Pattyn, F., Payne, A. J., Rodehacke, C., Rückamp, M., Saito, F., Schlegel, N., Seroussi, H., Shepherd, A., Sun, S., van de Wal, R., and Ziemen, F. A.: Design and results of the ice sheet model initialisation experiments initMIP-Greenland: an ISMIP6 intercomparison, The Cryosphere, 12, 1433-1460, https://doi.org/10.5194/tc-12-14332018, 2018.

Hofer, S., Tedstone, A. J., Fettweis, X., and Bamber, J. L.: Decreasing cloud cover drives the recent mass loss on the Greenland Ice Sheet, Science Advances, 3, e1700584, https://doi.org/10.1126/sciadv.1700584, 2017.

Howat, I. M., Negrete, A., and Smith, B. E.: The Greenland Ice Mapping Project (GIMP) land classification and surface elevation data sets, The Cryosphere, 8, 1509-1518, https://doi.org/10.5194/tc-8-1509-2014, 2014.

Joughin, I., Smith, B., Howat, I., and Scambos, T.: MEaSUREs Greenland Ice Velocity Map from InSAR Data, Tech. rep., National Snow and Ice Data Center, Boulder, Colorado USA, https://doi.org/10.5067/MEASURES/CRYOSPHERE/nsidc0478.001, 2010a.

Joughin, I., Smith, B., Howat, I. M., Scambos, T., and Moon, T.: Greenland Flow Variability from Ice-SheetWide Velocity Mapping, J. Glaciol., 56, 415-430, https://doi.org/10.3189/002214310792447734, 2010 b.

Kay, J. E. and Gettelman, A.: Cloud influence on and response to seasonal Arctic sea ice loss, J. Geophys. Res., 114, D18204, https://doi.org/10.1029/2009JD011773, 2009. 
Kennedy, J. H.: Input data processing for the Community Ice Sheet Model, version 2, available at: https://github.com/jhkennedy/ cism-data/releases/tag/v1.0.0-RC2 (last access: 5 March 2019), released 24 February 2017.

Kennedy, J. H., Bennett, A., Evans, K. J., Worley, P., Boghozian, A., Norman, M., Price, S. F., and Hoffman, M.: A pythonbased extensible toolkit for a robust verification and validation of continental-scale ice sheet models, J. Adv. Model. Earth Syst., 9, 854-869, https://doi.org/10.1002/2017MS000916, 2017.

Kennedy, J. H., Bennett, A., Evans, K., Price, S., Ranken, D., Norman, M., Fyke, J., Hoffman, M., and Lipscomb, W.: LIVVkit/LIVVkit: LIVVkit 2.1.6, Zenodo, https://doi.org/10.5281/zenodo.1322735, 2018a.

Kennedy, J. H., Evans, K. J., Forrester, M. M., and Bennett, A. R.: LIVVkit/LEX v0.1.0, Zenodo, https://doi.org/10.5281/zenodo.1937579, 2018b.

Koenig, L. S., Ivanoff, A., Alexander, P. M., MacGregor, J. A., Fettweis, X., Panzer, B., Paden, J. D., Forster, R. R., Das, I., McConnell, J. R., Tedesco, M., Leuschen, C., and Gogineni, P.: Annual Greenland accumulation rates (2009-2012) from airborne snow radar, The Cryosphere, 10, 1739-1752, https://doi.org/10.5194/tc-10-1739-2016, 2016.

Larour, E., Seroussi, H., Morlighem, M., and Rignot, E.: Continental scale, high order, high spatial resolution, ice sheet modeling using the Ice Sheet System Model (ISSM), J. Geophys. Res., 117, F01022, https://doi.org/10.1029/2011JF002140, 2012.

Lawrence, D. M., Oleson, K., Flanner, M., Fletcher, C. G., Lawrence, P., Levis, S., Swenson, S. C., and Bonan, G.: The CCSM4 Land Simulation, 1850-2005: Assessment of Surface Climate and New Capabilities, J. Climate, 25, 2240-2260, 2012.

Lenaerts, J. T. M., Tricht, K. V., Lhermitte, S., and L'Ecuyer, T. S.: Polar clouds and radiation in satellite observations, reanalyses, and climate models, Geophys. Res. Lett., 44, 3355-3364, https://doi.org/10.1002/2016GL072242, 2012.

Lewis, G., Osterberg, E., Hawley, R., Whitmore, B., Marshall, H. P., and Box, J.: Regional Greenland accumulation variability from Operation IceBridge airborne accumulation radar, The Cryosphere, 11, 773-788, https://doi.org/10.5194/tc-11773-2017, 2017.

Lipscomb, W., Fyke, J., Vizcaíno, M., Sacks, W., Wolfe, J., Vertenstein, M., Craig, A., Kluzek, E., and Lawrence, D.: Implementation and initial evaluation of the Glimmer Community Ice Sheet Model in the Community Earth System Model, J. Glaciol., 26, 7352-7371, 2013.

Lynnes, C. and Ramachandran, R.: Generalizing a Data Analysis Pipeline in the Cloud to Handle Diverse Use Cases in NASA's EOSDIS, in: IGARSS 2018 - 2018 IEEE International Geoscience and Remote Sensing Symposium, 22-27 July 2018, Valencia, Spain, 422-425, https://doi.org/10.1109/IGARSS.2018.8519178, 2018.

MacGregor, J. A., Fahnestock, M. A., Catania, G. A., Aschwanden, A., Clow, G. D., Colgan, W. T., Gogineni, S. P., Morlighem, M., Nowicki, S. M. J., Paden, J. D., Price, S. F., and Seroussi, H.: A synthesis of the basal thermal state of the Greenland Ice Sheet, J. Geophys. Res. Earth, 121, 1328-1350, https://doi.org/10.1002/2015JF003803, 2016.

Machguth, H., Thomsen, H. H., Weidick, A., Ahlstrøm, A. P., Abermann, J., Andersen, M. L., Andersen, S. B., Bjørk, A. A., Box, J. E., Braithwaite, R. J., Bøggild, C. E., Citterio, M., Clement,
P., Colgan, W., Fausto, R. S., Gleie, K., Gubler, S., Hasholt, B., Hynek, B., Knudsen, N. T., Larsen, S. H., Mernild, S. H., Oerlemans, J., Oerter, H., Olesen, O. B., Smeets, C. J. P. P., Steffen, K., Stober, M., Sugiyama, S., Van As, D., Van Denbroeke, M. R., and Van De Wal, R. S. W.: Greenland surface mass-balance observations from the ice-sheet ablation area and local glaciers, J. Glaciol., 62, 861-887, https://doi.org/10.1017/jog.2016.75, 2016.

Mahajan, S., Evans, K. J., Norman, M. R., and Gaddis, A. L.: Exploring an Ensemble-Based Approach to Atmospheric Climate Modeling and Testing at Scale, Procedia Comput. Sci., 108, 735744, 2017.

McGranahan, G., Balk, D., and Anderson, B.: The rising tide: Assessing the risks of climate change and human settlements in low elevation coastal zones, Environ. Urban., 19, 17-37, https://doi.org/10.1177/0956247807076960, 2007.

Morlighem, M., Rignot, E., Mouginot, J., Seroussi, H., and Larour, E.: Deeply incised submarine glacial valleys beneath the Greenland Ice Sheet, Nat. Geosci., 7, 418-422, https://doi.org/10.1038/ngeo2167, 2014.

Morlighem, M., Williams, C. N., Rignot, E., An, L., Arndt, J. E., Bamber, J. L., Catania, G., Chauché, N., Dowdeswell, J. A., Dorschel, B., Fenty, I., Hogan, K., Howat, I., Hubbard, A., Jakobsson, M., Jordan, T. M., Kjeldsen, K. K., Millan, R., Mayer, L., Mouginot, J., Noël, B. P. Y., O’Cofaigh, C., Palmer, S., Rysgaard, S., Seroussi, H., Siegert, M. J., Slabon, P., Straneo, F., van den Broeke, M. R., Weinrebe, W., Wood, M., and Zinglersen, K. B.: BedMachine v3: Complete Bed Topography and Ocean Bathymetry Mapping of Greenland From Multibeam Echo Sounding Combined With Mass Conservation, Geophys. Res. Lett., 44, 11051-11061, https://doi.org/10.1002/2017GL074954, 2017.

Neale, R., Richter, J., Park, S., Lauritzen, P., Vavrus, S. J., Rasch, P., and Zhang, M.: The mean climate of the Community Atmosphere Model (CAM4) in forced SST and fully coupled experiments, J. Climate, 26, 5150-5168, https://doi.org/10.1175/JCLID-12-00236.1, 2013.

Noël, B., van de Berg, W. J., van Meijgaard, E., Kuipers Munneke, P., van de Wal, R. S. W., and van den Broeke, M. R.: Evaluation of the updated regional climate model RACMO2.3: summer snowfall impact on the Greenland Ice Sheet, The Cryosphere, 9, 1831-1844, https://doi.org/10.5194/tc-9-1831-2015, 2015.

Nowicki, S. M. J., Payne, A., Larour, E., Seroussi, H., Goelzer, H., Lipscomb, W., Gregory, J., Abe-Ouchi, A., and Shepherd, A.: Ice Sheet Model Intercomparison Project (ISMIP6) contribution to CMIP6, Geosci. Model Dev., 9, 4521-4545, https://doi.org/10.5194/gmd-9-4521-2016, 2016.

Nowicki et al.: Cryosphere Model Comparison Tool $(\mathrm{CmCt})$, available at: https://ggsghpcc.sgt-inc.com/cmct/ (last access: 5 March 2019), 2017.

Oberkampf, W. L. and Roy, C. J.: Verification and Validation in Scientific Computing, Cambridge University Press, New York, 2010.

Ohmura, A. and Reeh, N.: New precipitation and accumulation maps for Greenland, J. Glaciol., 37, 140-148, 1991.

Ohmura, A., Calanca, P., Wild, M., and Anklin, M.: Preciptation, accumulation, and mass balance of the Greenland ice sheet, Zeitschrift für Gletscherkunde und Glazialgeologie, 35, 1-20, 1999. 
Overly, T. B., Hawley, R. L., Helm, V., Morris, E. M., and Chaudhary, R. N.: Greenland annual accumulation along the EGIG line, 1959-2004, from ASIRAS airborne radar and neutronprobe density measurements, The Cryosphere, 10, 1679-1694, https://doi.org/10.5194/tc-10-1679-2016, 2016.

Perego, M., Price, S., and Stadler, G.: Optimal Initial Conditions for Coupling Ice Sheet Models to Earth System Models, J. Geophys. Res.-Earth, 119, 1894-1917, 2014.

Pincus, R. and NCAR Research Staff (Eds): Climate Data Guide, National Center for Atmospheric Research, Boulder, CO, USA, available at: https://climatedataguide.ucar.edu/climate-data (last access: 5 March 2019), 2016.

Price, S., Lipscomb, W., Hoffman, M., Hagdorn, M., Rutt, I., Payne, T., Hebeler, F., and Kennedy, J. H.: CISM 2.0.5 Documentation, Los Alamos National Laboratory, Los Alamos, NM, USA, 2015.

Price, S. F., Hoffman, M. J., Bonin, J. A., Howat, I. M., Neumann, T., Saba, J., Tezaur, I., Guerber, J., Chambers, D. P., Evans, K. J., Kennedy, J. H., Lenaerts, J., Lipscomb, W. H., Perego, M., Salinger, A. G., Tuminaro, R. S., van den Broeke, M. R., and Nowicki, S. M. J.: An ice sheet model validation framework for the Greenland ice sheet, Geosci. Model Dev., 10, 255-270, https://doi.org/10.5194/gmd-10-255-2017, 2017.

Rossow, R. B. and Schiffer, R.: Advances in understanding clouds from ISCCP, B. Am. Meteorol. Soc., $\quad 80, \quad 2261-2287$, https://doi.org/10.1175/15200477(1999)080<2261:AIUCFI>2.0.CO;2, 1999.

Rutt, I., Hagdorn, M., Hulton, N. J. R., and Payne, A. J.: The Glimmer Community Ice Sheet Model, J. Geophys. Res., 114, F02004, https://doi.org/10.1029/2008JF001015, 2009.

Schoof, C. and Hewitt, I.: Ice-Sheet Dynamics, Annu. Rev. Fluid Mech., 45, 217-239, https://doi.org/10.1146/annurevfluid-011212-140632, 2013.

Stark, J. D., Donlon, C. J., Martin, M. J., and McCulloch, M. E.: OSTIA: An operational, high resolution, real time, global sea surface temperature analysis system, in: OCEANS 2007 - Europe, Aberdeen, UK, 18-21 June 2007, IEEE, 1-4, https://doi.org/10.1109/OCEANSE.2007.4302251, 2007.

SUMup: Surface Mass Balance and Snow on Sea Ice Working Group, available at: https://neptune.gsfc.nasa.gov/csb/index. php?section=267 (last access: 5 March 2019), 2018.

Terrizzano, I. G., Schwarz, P. M., Roth, M., and Colino, J. E.: Data Wrangling: The Challenging Journey from the Wild to the Lake, in: CIDR, 4-7 January 2015, Asilomar, CA, USA, 2015.

Tezaur, I. K., Perego, M., Salinger, A. G., Tuminaro, R. S., and Price, S. F.: Albany/FELIX: a parallel, scalable and robust, finite element, first-order Stokes approximation ice sheet solver built for advanced analysis, Geosci. Model Dev., 8, 1197-1220, https://doi.org/10.5194/gmd-8-1197-2015, 2015a.
Tezaur, I. K., Tuminaro, R. S., Perego, M., Salinger, A. G., and Price, S. F.: On the scalability of the Albany/FELIX first-order Stokes Approximation ice Sheet Solver for Large-Scale Simulations of the Greenland and Antarctic ice sheets, Procedia Comput. Sci., 51, 2026-2035, 2015b.

van Angelen, J. H., Broeke, M. V. D., Wouters, B., and Lenaerts, J. T. M.: Contemporary (1960-2012) Evolution of the Climate and Surface Mass Balance of the Greenland Ice Sheet, Surv. Geophys., 35, 1155-1174, 2013.

van de Wal, R. S. W., Boot, W., Smeets, C. J. P. P., Snellen, H., van den Broeke, M. R., and Oerlemans, J.: Twenty-one years of mass balance observations along the K-transect, West Greenland, Earth Syst. Sci. Data, 4, 31-35, https://doi.org/10.5194/essd-431-2012, 2012.

Van Tricht, K., Lhermitte, S., Lenaerts, J. T. M., Gorodetskaya, I. V., L'Ecuyer, T. S., Noël, B., van den Broeke, M. R., Turner, D. D., and van Lipzig, N. P. M.: Clouds enhance Greenland ice sheet meltwater runoff, Nat. Commun., 7, 10266, https://doi.org/10.1038/ncomms10266, 2016.

Vertenstein, M., Bertini, A., Craig, T., Edwards, J., Levy, M., Mai, A., and Schollenberger, J.: CESM User's Guide (CESM1.2 Release Series User's Guide), available at: http://www.cesm.ucar.edu/models/cesm1.2/cesm/doc_cesm1_ 2_1/usersguide/book1.html (last access: 5 March 2019), 2013.

Vizcaíno, M.: Ice sheets as interactive components of Earth System Models: progress and challenges, WIREs Clim. Change, 5, 557568, https://doi.org/10.1002/wcc.285, 2014.

Vizcaíno, M., Lipscomb, W. H., Sacks, W., van Angelen, J. H., Wouters, B., and van den Broeke, M. R.: Greenland Surface Mass Balance as Simulated by the Community Earth System Model. Part I: Model Evaluation and 1850-2005 Results, J. Climate, 26, 7993-7812, https://doi.org/10.1175/JCLI-D-12-00615.1, 2013.

Zender, C. S.: Analysis of Self-describing Gridded Geoscience Data with netCDF Operators (NCO), Environ. Modell. Softw., 23, 1338-1342, https://doi.org/10.1016/j.envsoft.2008.03.004, 2008.

Ziemen, F. A., Rodehacke, C. B., and Mikolajewicz, U.: Coupled ice sheet-climate modeling under glacial and preindustrial boundary conditions, Clim. Past, 10, 1817-1836, https://doi.org/10.5194/cp-10-1817-2014, 2014.

Zwally, H. J., Giovinetto, M. B., Beckley, M. A., and Saba, J. L.: Antarctic and Greenland Drainage Systems, GSFC Cryospheric Sciences Laboratory, Geenbelt, MD, USA, available at: http:// icesat4.gsfc.nasa.gov/cryo_data/ant_grn_drainage_systems.php (last access: 5 March 2019), 2012. 